\title{
Structural and biological insights into Klebsiella pneumoniae surface polysaccharide degradation by a bacteriophage K1 lyase: implications for clinical use
}

I-Fan Tu ${ }^{1 \dagger}$, Tzu-Lung Lin ${ }^{2 \dagger}$, Feng-Ling Yang ${ }^{1}$, I-Ming Lee ${ }^{1}$, Wei-Lin Tu' ${ }^{1}$, Jiahn-Haur Liao ${ }^{1}$, Tzu-Ping Ko ${ }^{1}$, Wen-Jin Wu' ${ }^{1}$, Jia-Tsrong Jan ${ }^{3}$, Meng-Ru Ho ${ }^{1}$, Ching-Yi Chou ${ }^{1}$, Andrew H.-J. Wang ${ }^{1}$, Chung-Yi Wu ${ }^{3}$, Jin-Town Wang ${ }^{2}$, Kai-Fa Huang ${ }^{1 *}$ (D) and Shih-Hsiung Wu $\mathbf{W}^{1,4^{*}}$

\begin{abstract}
Background: K1 capsular polysaccharide (CPS)-associated Klebsiella pneumoniae is the primary cause of pyogenic liver abscesses (PLA) in Asia. Patients with PLA often have serious complications, ultimately leading to a mortality of $\sim 5 \%$. This K1 CPS has been reported as a promising target for development of glycoconjugate vaccines against $K$. pneumoniae infection. The pyruvylation and O-acetylation modifications on the K1 CPS are essential to the immune response induced by the CPS. To date, however, obtaining the fragments of K1 CPS that contain the pyruvylation and $\mathrm{O}$-acetylation for generating glycoconjugate vaccines still remains a challenge.

Methods: We analyzed the digested CPS products with NMR spectroscopy and mass spectrometry to reveal a bacteriophage-derived polysaccharide depolymerase specific to K1 CPS. The biochemical and biophysical properties of the enzyme were characterized and its crystal structures containing bound CPS products were determined. We also performed site-directed mutagenesis, enzyme kinetic analysis, phage absorption and infectivity studies, and treatment of the K. pneumoniae-infected mice with the wild-type and mutant enzymes.

Results: We found a bacteriophage-derived polysaccharide lyase that depolymerizes the K1 CPS into fragments of 1-3 repeating trisaccharide units with the retention of the pyruvylation and O-acetylation, and thus the important antigenic determinants of intact K1 CPS. We also determined the 1.46-Å-resolution, product-bound crystal structure of the enzyme, revealing two distinct carbohydrate-binding sites in a trimeric $\beta$-helix architecture, which provide the first direct evidence for a second, non-catalytic, carbohydrate-binding site in bacteriophage-derived polysaccharide depolymerases. We demonstrate the tight interaction between the pyruvate moiety of K1 CPS and the enzyme in this second carbohydrate-binding site to be crucial to CPS depolymerization of the enzyme as well as phage absorption and infectivity. We also demonstrate that the enzyme is capable of protecting mice from K1 K. pneumoniae infection, even against a high challenge dose.
\end{abstract}

\footnotetext{
*Correspondence: huangkf@gate.sinica.edu.tw; shwu@gate.sinica.edu.tw

${ }^{\dagger}$-Fan Tu and Tzu-Lung Lin contributed equally to this work.

${ }^{1}$ Institute of Biological Chemistry, Academia Sinica, No. 128 Academia

Road Section 2, Nan-Kang, Taipei 115, Taiwan

Full list of author information is available at the end of the article
} permits use, sharing, adaptation, distribution and reproduction in any medium or format, as long as you give appropriate credit to the original author(s) and the source, provide a link to the Creative Commons licence, and indicate if changes were made. The images or other third party material in this article are included in the article's Creative Commons licence, unless indicated otherwise in a credit line to the material. If material is not included in the article's Creative Commons licence and your intended use is not permitted by statutory regulation or exceeds the permitted use, you will need to obtain permission directly from the copyright holder. To view a copy of this licence, visit http://creativecommons.org/licenses/by/4.0/. The Creative Commons Public Domain Dedication waiver (http://creativeco mmons.org/publicdomain/zero/1.0/) applies to the data made available in this article, unless otherwise stated in a credit line to the data. 
Conclusions: Our results provide insights into how the enzyme recognizes and depolymerizes the K1 CPS, and demonstrate the potential use of the protein not only as a therapeutic agent against $K$. pneumoniae, but also as a tool to prepare structurally-defined oligosaccharides for the generation of glycoconjugate vaccines against infections caused by this organism.

Keywords: Klebsiella pnuemoniae, K1 capsular polysaccharide, Tailspike protein, Polysaccharide lyase, Pyruvylation, Acetylation, $\beta$-Helix

\section{Background}

For more than two decades, pathogenic Klebsiella pneumoniae has been a community-acquired infection causing pyogenic liver abscesses (PLAs) in Asia. Patients with PLA often have serious complications, such as endophthalmitis, meningitis, and necrotizing fasciitis, ultimately leading to a mortality of $\sim 5 \%$ [1]. Survivors of PLA-associated meningitis and endophthalmitis usually suffer from either severe neurological sequelae or blindness, respectively. Previous studies indicated that nearly all PLA $K$. pneumoniae strains possess a hypermucovisous phenotype attributed to their unique capsular polysaccharides (CPSs) [2], particularly the K1 CPS [3]. As an alternative to treatment with antibiotics, monoclonal antibodies against the K1 CPS of K. pneumoniae can enhance phagocytosis to combat invasion of the bacterium and protected mice from K. pneumoniaeinduced liver abscess and lethality [4], suggesting that the $\mathrm{K} 1 \mathrm{CPS}$ is a promising target for vaccine development against $K$. pneumoniae infection [5]. On the basis of previous studies, however, whole CPS isolates from pathogenic bacteria could only induce relatively poor and $\mathrm{T}$ cell-independent immune responses [6]. In contrast, glycoconjugate vaccines generated by conjugating CPS to a carrier protein can elicit a stronger and long-lasting immune response [7-9].

The chemical structure of the K1 CPS comprises repeating units of the trisaccharide $(\rightarrow 3)-\beta-D-$ Glcp-(1 $\rightarrow 4)$-[2,3-(S)-pyruvate]- $\beta$-D-GlcpA- $(1 \rightarrow 4)-\alpha-\mathrm{L}-$ Fucp- $(1 \rightarrow)$. The pyruvylation of the glucuronic acid and $\mathrm{O}$-acetylation of the fucose are essential to the immune response induced by the K1 CPS [10]. In an attempt to fragment K1 CPS into oligosaccharides via chemical methods, we failed to retain the pyruvylation and $O$-acetylation modifications in the products [10]. Recently, the development of a K1 CPS-containing glycoconjugate vaccine against $\mathrm{K} 1 \mathrm{~K}$. pneumonia infection was reported [11]. The polysaccharide was enzymatically produced in glycoengineered Escherichia coli, but a low degree of pyruvylation was observed. Thus, alternate ways of accessing these glycans are important.

Many bacteriophages depolymerize the CPS of their host bacteria through their tailspike proteins (TSPs) [12]. The digested products usually comprise oligosaccharides with some repeating units, which retain the immunogenicity of CPS [13, 14]. In earlier work, we isolated a bacteriophage (NTUH-K2044-K1-1) whose genome encodes a K1 CPS-specific depolymerase [15]. Administration of this phage or the recombinant CPS depolymerase provided significantly increased survival in mice infected with the K1 K. pneumoniae NTUH-K2044 or an extended-spectrum $\beta$-lactamase (ESBL)-producing K1 strain [15]. Further investigation demonstrated that the CPS depolymerase removed the capsule from $K$. pneumoniae in vivo, enabling the host immune system to kill the bacterium, implicating the therapeutic potential of the enzyme against $K$. pneumonia [16].

In the present study, we analyzed the digested products of K1 CPS with NMR spectroscopy and mass spectrometry to reveal that the NTUH-K2044-K1-1 CPS depolymerase is a K1 lyase. Crystal structures of the enzyme containing bound products revealed two distinct carbohydrate-binding sites with unusual features compared to other TSP depolymerases. Through site-directed mutagenesis, phage absorption and infectivity studies, and treatment of the K. pneumoniae-infected mice with the mutant enzymes, we have obtained deeper insights into how this enzyme recognizes and depolymerizes $\mathrm{K} 1$ CPS on the surface of K. pneumoniae.

\section{Materials and methods}

\section{Protein production}

The gene orf34 (Genbank: BAP15746) of bacteriophage NTUH-K2044-K1-1, which encodes the K1 CPS-specific depolymerase K1 lyase (amino acids 1-651), was amplified and sequenced as described previously [15]. The orf34 DNA was inserted into the vector pET28a (Novagen) via NdeI and $X h o \mathrm{I}$ cloning sites and the vector was transformed into the E. coli BL21 (DE3) (Novagen). The cells were grown in Luria- Bertani (LB) medium supplemented with $50 \mu \mathrm{g} / \mathrm{mL}$ kanamycin at $37{ }^{\circ} \mathrm{C}$ until the cell density reached OD600 of 0.4-0.6. The cultured cells were induced with $0.4 \mathrm{mM} \mathrm{IPTG}$ at $20^{\circ} \mathrm{C}$ for $12-16 \mathrm{~h}$. Then, the cells were harvested by centrifugation $(6,000 \mathrm{rpm})$ at $4{ }^{\circ} \mathrm{C}$ for $30 \mathrm{~min}$ and suspended in buffer A (25 mM Tris- $\mathrm{HCl}$ and $100 \mathrm{mM} \mathrm{NaCl}, \mathrm{pH}$ 7.5). The cells were lysed by passing through a French Press (Constant System Ltd, Constant System TS 2.2kw) three times 
and the lysate was clarified by centrifugation (9000 rpm) at $4{ }^{\circ} \mathrm{C}$ for $30 \mathrm{~min}$. The supernatant was loaded onto an open column filled with nickel-chelating Sepharose resin (GE Healthcare) pre-equilibrated with buffer A. The column was washed with buffer B $(25 \mathrm{mM}$ Tris- $\mathrm{HCl}$, $100 \mathrm{mM} \mathrm{NaCl}$ and $90 \mathrm{mM}$ imidazole, $\mathrm{pH}$ 7.5) and the recombinant protein was eluted with buffer $\mathrm{C}(25 \mathrm{mM}$ Tris- $\mathrm{HCl}, 100 \mathrm{mM} \mathrm{NaCl}$ and $200 \mathrm{mM}$ imidazole, $\mathrm{pH}$ 7.5). The eluted fractions were pooled and then dialyzed against buffer $\mathrm{D}$ [ $25 \mathrm{mM}$ Tris- $\mathrm{HCl}, 100 \mathrm{mM} \mathrm{NaCl}$ and $10 \%(\mathrm{v} / \mathrm{v})$ glycerol, $\mathrm{pH} 7.5$ ] at $4{ }^{\circ} \mathrm{C}$ for $12 \mathrm{~h}$. The recombinant protein was further purified by a Superdex-200 gel-filtration column (GE-Healthcare), leading to near homogeneity. Site-directed mutagenesis experiments were conducted by using the QuikChange II site-directed mutagenesis Kit (Stratagene) and following the manufacturer's instruction. Protein concentration was measured spectrophotometrically on the basis of the extinction coefficient $84,230 \mathrm{~cm}^{-1} \mathrm{M}^{-1}$ calculated from the protein sequence [17].

\section{Agar overlay assay}

Agar overlay assay was performed according to a previous protocol [18]. Briefly, LB agar in a petri dish was overlaid with $5 \mathrm{~mL}$ of top agar, which was pre-incubated with fresh culture of $K$. pneumoniae NTUH-K2044 and an adequate amount of phage. After an overnight incubation at $37{ }^{\circ} \mathrm{C}$, the infectivity of phage was evaluated by measuring the dimension of clear zone plus surrounded translucent halo on the surface of agar.

\section{Extraction of $\mathrm{K} 1 \mathrm{CPS}$}

We used the K. pneumoniae strain NTUH-K2044 $\Delta$ wbbO to extract the K1 CPS, because this strain lacks the $\mathrm{O}$-antigen in lipopolysaccharide and thus avoids the contamination of lipopolysaccharide The protocol of extraction was referring to a previous report [10]. Briefly, the bacteria were collected from an overnight culture on solid agar and suspended in distilled water. The suspension was heated at $100{ }^{\circ} \mathrm{C}$ for $10 \mathrm{~min}$ and then cooled down to room temperature. The bacterial debris was removed by centrifugation at $15000 x g$ for $20 \mathrm{~min}$. The polysaccharide in the supernatant was precipitated by adding ice-cold acetone, and crude extract of K1 CPS was obtained by centrifugation at $12,000 \times g$ for $20 \mathrm{~min}$. The crude extract was incubated with ribonuclease (Roche) and deoxyribonuclease I (Roche) at $37{ }^{\circ} \mathrm{C}$ for $24 \mathrm{~h}$, and added with protease $\mathrm{K}$ in $10 \mathrm{mM}$ Tris- $\mathrm{HCl}, \mathrm{pH} 7.4$, and then further incubated for $6-8 \mathrm{~h}$. After heated at $100{ }^{\circ} \mathrm{C}$ for $10 \mathrm{~min}$ and clarified by centrifugation, the supernatant was dialyzed extensively against water using an 8-10 kDa cutoff membrane and lyophilized. Prior to mass spectrometry analysis and enzymatic assays, the K1
CPS was further purified by a TSK HW-65F gel-filtration column.

\section{NMR sample preparation and data collection}

Seven $\mathrm{mg}$ of the K1 lyase-digested products was dissolved in $300 \mu \mathrm{D}_{2} \mathrm{O}$ containing $33 \mu \mathrm{M}$ DSS as an internal chemical shift standard, with the $\mathrm{pH}$ value of the sample being 4.65. The 2D DQF-COSY spectrum of the products was collected at $298 \mathrm{~K}$ on a Bruker $800 \mathrm{MHz}$ NMR spectrometer equipped with a cryogenic probe. All experiments were carried out with the standard pulse sequences provided by Bruker software and the responsive data were processed with Bruker TopSpin program. The data acquisition parameters are as follow: 2048 (F2) by 512 (F1, increments) data matrix, 56 scans for each increment, $9 \mathrm{ppm}$ spectral width in both dimensions. Data processing parameters are as follow: 4096 (F2) by 1024 (F1) data matrix. A 60-degree shifted sinebell window function was applied in both dimensions.

\section{Dot blot analysis}

Antiserum raised against the K1 CPS was obtained from the Laboratory of HealthCare Associated Infection, Health Protection Agency [19]. Column-purified K1 CPS and its K1 lyase-digested products with quantities in the range of 0.1 to $500 \mu \mathrm{g}$ were loaded onto a PVDF membrane $(0.45 \mu \mathrm{m}$, Immobilon-P, Millipore) by using a vacuum-driven slot blot filtration manifold (Hoefer). The membrane was blocked with $5 \%$ non-fat milk dissolved in 1X PBS buffer at room temperature for $1 \mathrm{~h}$ and then incubated with the antiserum $(1 /: 10,000$ dilution by $0.1 \%$ Tween 20 in $1 \times$ PBS) for $1 \mathrm{~h}$. Subsequently, the membrane was incubated with a secondary antibody (1:20,000 dilution by $0.1 \%$ Tween 20 in $1 \times$ PBS) for $1 \mathrm{~h}$ and the chemiluminescence-based immunodetection was performed by using the substrate ECL (Millipore).

\section{Mass spectrometry analysis}

Mass spectrometry analyses were performed at the Mass Core Facility of Genomics Research Center, Academia Sinica (Taipei, Taiwan). LC-ESI-MS and LCESI-MS-MS analyses were done on a LTQ Orbitrap XL ETD mass spectrometer (Thermo Fisher Scientific, San Jose, CA) equipped with standard ESI ion source. $5 \mu \mathrm{L}$ of sample in $80 \% \mathrm{ACN} / \mathrm{H}_{2} \mathrm{O}$ and $0.1 \%$ FA was injected at a flow rate of $50 \mu \mathrm{L} / \mathrm{min}$ by Ultimate 3000 RSLC system (Dionex Corporation, Sunnyvale, CA). The conditions for full-scan MS are as follows: mass range $\mathrm{m} / \mathrm{z}$ 100-2000 and resolution 60,000 at $\mathrm{m} / \mathrm{z} 400$. The target ions were sequentially isolated for MS2 by LTQ. Electrospray voltage was maintained at $4 \mathrm{kV}$ and capillary temperature was set at $275^{\circ} \mathrm{C}$. 


\section{Thermal stability analysis}

The thermal stability of recombinant enzymes was evaluated by monitoring the change of circular dichroism (CD) spectra under various temperatures. The $\mathrm{CD}$ experiments were performed on a J815 spectrometer (Jasco) using a $10 \mathrm{~mm}$-path quartz cuvette. The recombinant enzyme at the concentration of $3 \mu \mathrm{M}$ in $30 \mathrm{mM}$ sodium phosphate

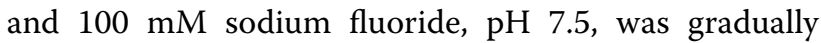
heated from 25 to $95{ }^{\circ} \mathrm{C}$ at a speed of $1{ }^{\circ} \mathrm{C} / \mathrm{min}$, and the CD spectrum between 260 and $200 \mathrm{~nm}$ at each temperature was recorded at a scan speed of $20 \mathrm{~nm} / \mathrm{min}$ and a data pitch of $0.5 \mathrm{~nm}$. The obtained spectra were further smoothed and normalized by using the software Spectra Manager (Jasco). The melting point temperature was estimated by measuring the change of mean residue ellipticity at $216 \mathrm{~nm}$ for the gradually elevated temperatures.

\section{Analytical ultracentrifugation analysis}

Ultracentrifugation sedimentation experiments were performed at $20{ }^{\circ} \mathrm{C}$ and at 20,000 rpm in a Beckman XL-A analytical ultracentrifuge (Beckman Instruments, Fullerton, Calif, USA) equipped with the standard doublesector centerpieces and using an An-60 Ti rotor. The UV absorption at $280 \mathrm{~nm}$ was scanned every $4 \mathrm{~min}$ for 250 scans. The data were analyzed with the software SEDFIT. The protein sample was in a buffer of $25 \mathrm{mM}$ Tris$\mathrm{HCl}$ and $100 \mathrm{mM} \mathrm{NaCl}, \mathrm{pH}$ 7.5. The sample was visually checked for clarity after ultracentrifugation. No precipitation was observed.

\section{Enzyme activity assay}

The enzymatic activity of K1 lyase on the substrate K1 CPS was evaluated by monitoring the elevated UV absorption at $232 \mathrm{~nm}$, since the degraded products contained unsaturated oligosaccharides [12]. The assay was performed at $25{ }^{\circ} \mathrm{C}$ in an Ultrospec $4000 \mathrm{UV} /$ Visible spectrophotometer (Amersham Pharmacia Biotech, Piscataway, NJ, USA) using an $1 \mathrm{ml}$ cuvette. The reaction was started by adding the recombinant enzyme $(10 \mu \mathrm{g} /$ $\mathrm{ml})$ to the mixture containing $40 \mu \mathrm{g} / \mathrm{ml} \mathrm{K1} \mathrm{CPS} \mathrm{and}$ $3 \mathrm{mM} \mathrm{MgCl}_{2}$ in $25 \mathrm{mM}$ Tris- $\mathrm{HCl}, \mathrm{pH}$ 7.5. The increase in $\mathrm{UV}_{232}$ absorption was monitored for $15 \mathrm{~min}$. Since the CPS extracts were heterogeneous, the enzymatic activity was represented as $\Delta \mathrm{A}_{232} \cdot \mathrm{min}^{-1} \cdot \mathrm{mg}^{-1}$.

The enzyme kinetic study of $\mathrm{K} 1$ lyase and its mutant was conducted by measuring the production of reducing sugars using 3-methyl-2-benzothiazolinehydrazone (MBTH) [20]. A 20- $\mu$ l reaction mixture containing $10 \mu \mathrm{g} / \mathrm{ml}$ enzyme and $\mathrm{K} 1 \mathrm{CPS}$ at varying concentrations $(0-6.5 \mathrm{mg} / \mathrm{ml})$ was incubated at $25^{\circ} \mathrm{C}$ for $3 \mathrm{~min}$ and then added with $0.5 \mathrm{~N} \mathrm{NaOH}$ to stop the reaction. Subsequently, the reaction mixture was added with dithiotreitol/MBTH solution (1:3 $\mathrm{mg} / \mathrm{ml}$ ratio, Sigma-aldrich) and then heated at $80{ }^{\circ} \mathrm{C}$ for $15 \mathrm{~min}$. After heating, the mixture was treated with the solution containing $0.5 \%$ ammonium iron(III) sulfate, $0.5 \%$ sulfamic acid and $0.25 \mathrm{~N} \mathrm{HCl}$, and then cooling down to room temperature. The initial velocity of the reactions was determined by monitoring the change of A620 using a Tecan Infinite M1000 pro (Tecan, Männedorf, Switzerland). Since possible product inhibition was observed for wild-type K1 lyase, the equation $v_{0}=V_{\max }[\mathrm{S}] /\left(K_{\mathrm{m}}+[\mathrm{S}]+[\mathrm{S}]^{5} / K_{\mathrm{i}}^{4}\right)$ was used to fit the initial velocity $\left(v_{0}\right)$ data by nonlinear regression with the software KaleidaGraph (Synergy Software, Reading, Pennsylvania, USA), where $V_{\max }$ is the limiting rate, $\mathrm{S}$ the substrate concentration, $K_{\mathrm{m}}$ the Michaelis constant, and $K_{\mathrm{i}}$ the inhibition constant [21]. Because no significant product inhibition was observed for the R472A mutant, the equation $v_{0}=V_{\max }[\mathrm{S}] /\left(K_{\mathrm{m}}+[\mathrm{S}]\right)$ was used to fit the initial velocity data to obtain the $K_{\mathrm{m}}$ and $V_{\max }$ values. The $k_{\text {cat }}$ values were calculated by $V_{\max }$ dividing to enzyme concentration. Correlation coefficients of better than 0.955 were obtained throughout the fittings.

\section{Crystallization and X-ray data collection}

Purified K1 lyase was concentrated to $\sim 15 \mathrm{mg} / \mathrm{mL}$ and subjected to crystallization screening using $\sim 1,000$ conditions at the Protein X-ray Crystallography Facility, Institute of Biological Chemistry, Academia Sinica (Taipei, Taiwan). The resulting hit conditions were further refined manually. Finally, two crystallization conditions were selected: (i) 15\% (w/v) PEG4000, 0.2 M imidazole malate, $\mathrm{pH}$ 6.0, and (ii) $15 \%(\mathrm{w} / \mathrm{v})$ PEG6000, $0.1 \mathrm{M}$ citrate (pH 5.5), and $0.019 \mathrm{M}$-decyl-N,N-dimethylglycine. The crystals were grown at $20{ }^{\circ} \mathrm{C}$ by mixing the protein solution with equal volume of crystallization buffers via the sitting-drop vapor-diffusion method. For condition (i), the rod-like crystals with dimensions reaching $0.15 \times 0.10 \times 0.10 \mathrm{~mm}$ appeared within 3 days; for condition (ii), plate-shaped crystals with dimensions reaching $0.25 \times 0.20 \times 0.05 \mathrm{~mm}$ appeared in one day. Since the crystals grown in condition (i) diffracted X-ray stronger, we used the crystals to solve the phase problem and to carry out the soaking experiments with K1 CPS. A multiple wavelength anomalous dispersion (MAD) data at $1.95-\AA$ resolution was collected at the beamline $44 \mathrm{XU}$ of SPring-8 (Hyogo, Japan), using Pt-labeled crystals obtained by soaking the crystals in $2 \mathrm{mM} \mathrm{K}_{2} \mathrm{Pt}(\mathrm{CNS})_{6}$ at $20{ }^{\circ} \mathrm{C}$ for 3 days. The high-resolution X-ray data were collected at the beamline 13B1 of National Synchrotron Radiation Research Center (NSRRC) (Hsinchu, Taiwan) and the Molecular Biology Consortium beamline of Advanced Light Source (Berkeley, USA). For structure of product-bound K1 lyase, the crystals were soaked in crude extract of $K$. pneumoniae K1 CPS (0.5 mg/ $\mathrm{mL}$ ) at $20{ }^{\circ} \mathrm{C}$ for $24 \mathrm{~h}$, and the X-ray data were collected 
at the NSRRC beamlines $15 \mathrm{~A} 1,13 \mathrm{~B} 1$, or $13 \mathrm{C} 1$, and the SPring- 8 beamline 12B2. Before mounting on the goniometer, the crystals were briefly immersed in reservoir solution containing $10 \%(\mathrm{v} / \mathrm{v})$ glycerol as cryoprotectant. All diffraction data were processed and scaled with the $H K L-2000$ package [22]. The data collection statistics are listed in Table 1. The space group for crystals grown in condition (i) and (ii) is $P 1$ and $C 2$, respectively, with asymmetric unit comprising 2 and $4 \mathrm{~K} 1$ lyase trimers. The cryoprotectant for crystals of condition (ii) was $15 \%$ $(\mathrm{v} / \mathrm{v})$ glycerol.

\section{Structure determination and refinement}

The crystal structure of $\mathrm{K}$ lyase was solved by the MAD-phasing method using the X-ray data collected at the wavelengths of inflection and high-energy remote of Pt. The positions of $23 \mathrm{Pt}$ atoms in the asymmetry unit, with occupancies between 0.1 and 1.0, were determined with Shelx $C / D$ and refined with $B P 3[23,24]$. The initial phases were improved by density modification with Solomon [25]. Approximate 84\% model was then automatically traced into the electron density map with Buccaneer [26], and the remainder was manually built with Coot [27]. The resulting model was subjected to computational refinement with the program REFMAC5 [28]. Throughout refinement, a randomly selected $5 \%$ of the data was set aside as a free data set, and the model was refined against the remaining data with $F>0$ as a working data set. Subsequently, iterative rounds of model adjustment with Coot and refinement

Table 1 Data collection and refinement statistics

\begin{tabular}{|c|c|c|c|c|c|}
\hline & \multicolumn{2}{|l|}{ Pt derivative } & \multirow{2}{*}{$\begin{array}{l}\text { Native } \\
\text { P1 crystal form }\end{array}$} & \multirow{2}{*}{$\begin{array}{l}\text { Native } \\
\text { C2 crystal form }\end{array}$} & \multirow{2}{*}{$\begin{array}{l}\text { Product-bound } \\
\text { P1 crystal form }\end{array}$} \\
\hline & High energy remote & Inflection & & & \\
\hline \multicolumn{6}{|l|}{ Data collection } \\
\hline Wavelength $(\AA ̊)$ & 1.05372 & 1.07194 & 1.0 & 1.0 & 1.0 \\
\hline Space group & $P 1$ & $P 1$ & $P 1$ & $C 2$ & $P 1$ \\
\hline Resolution (Å) & $30-1.95$ & $30-1.95$ & $30-1.48$ & $30-2.78$ & $30-1.46$ \\
\hline \multicolumn{6}{|l|}{ Unit cell dimensions } \\
\hline$a, b, c(\AA)$ & $90.77,100.83,125.38$ & $90.79,100.84,125.40$ & $90.28,100.57,125.03$ & $363.95,239.63,121.63$ & $90.63,100.99,125.38$ \\
\hline$a, \beta, \delta\left(^{\circ}\right)$ & $80.50,70.34,83.74$ & $80.50,70.34,83.74$ & $80.50,70.32,83.43$ & $90,100.13,90$ & $80.40,70.48,83.99$ \\
\hline Total observations & $1,733,160$ & $1,720,628$ & $2,458,178$ & 834,222 & $1,333,537$ \\
\hline Unique reflections & 291,399 & 291,203 & 656,693 & 257,393 & 673,887 \\
\hline Multiplicity & $5.9(5.9)$ & $5.9(5.9)$ & $3.7(3.7)$ & $3.2(3.2)$ & $2.0(2.0)$ \\
\hline Completeness (\%) & $97.7(96.3)$ & $97.7(96.2)$ & $97.0(95.4)$ & 99.7 (99.9) & $94.4(92.9)$ \\
\hline $1 / \sigma(I)$ & $21.96(4.81)$ & $21.27(4.30)$ & $25.44(2.28)$ & $11.24(2.47)$ & $19.84(2.14)$ \\
\hline$R_{\text {merge }}(\%)$ & $15.0(76.8)$ & $15.3(82.6)$ & $7.3(74.1)$ & $13.9(62.5)$ & $3.2(24.3)$ \\
\hline \multicolumn{6}{|l|}{ Refinement } \\
\hline Resolution $(\AA ̊)$ & & & $30.0-1.48$ & $29.95-2.78$ & $23.27-1.46$ \\
\hline Reflections [ $>0 \sigma(F)]$, working/test & & & $590,498 / 32,922$ & $228,380 / 12,744$ & $606,381 / 33,731$ \\
\hline$R$ factor $/ R_{\text {free }}$ & & & $0.137 / 0.184$ & $0.182 / 0.219$ & $0.114 / 0.148$ \\
\hline $\begin{array}{l}\text { R.m.s.d., bond lengths }(\AA) / \text { angles } \\
\left({ }^{\circ}\right)\end{array}$ & & & $0.018 / 1.697$ & $0.017 / 1.851$ & $0.009 / 1.514$ \\
\hline \multicolumn{6}{|l|}{$\begin{array}{l}\text { Average } B \text { factor }\left(\AA^{2}\right) / \text { No. of } \\
\text { atoms }\end{array}$} \\
\hline Protein & & & $21.1 / 28,967$ & 29.9/58385 & $16.7 / 29,026$ \\
\hline Sugar and other ligands & & & $35.0 / 286$ & $58.3 / 220$ & $27.0 / 534$ \\
\hline Water & & & $36.8 / 4,043$ & $26.3 / 1344$ & $33.4 / 4914$ \\
\hline \multicolumn{6}{|l|}{$\begin{array}{l}\text { Ramachandran plot, residues } \\
\text { in (\%) }\end{array}$} \\
\hline Most favored regions & & & 89.1 & 84.3 & 89.2 \\
\hline Additionally allowed regions & & & 10.1 & 14.7 & 10.0 \\
\hline Generously allowed regions & & & 0.8 & 1.0 & 0.8 \\
\hline Disallowed regions & & & 0.0 & 0.0 & 0.0 \\
\hline PDB code & & & 7W1C & 7W1D & 7W1E \\
\hline
\end{tabular}

Values in parentheses correspond to the highest resolution shell 
with REFMAC5 were performed using the 1.48 - $\AA$ resolution data set to improve the quality and completeness of the structure. The well-ordered water molecules were located with Coot. Finally, the refinement converged at a final $R$ factor and $R_{\text {free }}$ of 0.137 and 0.184 , respectively. The stereochemical quality of the refined structure was checked with the program PROCHECK [29]. The final refinement statistics are listed in Table 1. Regarding the structure of product-bound form, the initial difference Fourier map was obtained by using the refined structure. For the structure of $C 2$ crystal form, the initial phase was obtained by the molecular replacement phasing method with Molrep and using a K1 lyase trimer as the search model [30]. The subsequent model building and refinements were the same as described above. The molecular figures were generated with PyMOL (Schrödinger, New York, USA).

\section{Generation of mutant phages}

The protocol of site-directed mutagenesis to the genome of phage NTUH-K2044-K1-1 was referring to a previous study with some modifications [31]. A trimethoprim resistant gene (DHFR) was cloned into an ApaL1 site of the plasmid pKD46 carrying phage $\lambda$ Red recombinase under an inducible arabinose promoter which can promote the recombination [32, 33]. The resulted DHFR-pKD46 was transformed into the K. pneumoniae strain NTUH-K2044 via electroporation. The plasmids orf34 R378A::pET28c and orf34 R472A::pET28c, serving as the substrates of recombination, were transformed into the NTUH-K2044/ DHFR-pKD46 cell.

The NTUH-K2044/DHFR-pKD46 cell carrying the plasmid orf34 R378A::pET28c or orf34 R472A::pET28c was induced by $1 \mathrm{mM}$ arabinose for $3 \mathrm{~h}$ and then infected with phage NTUH-K2044-K1-1 at a titer of $100 \mathrm{pfu}$ (plaque forming unit) via the agar overlay method. Among the resulting single plaques of phage, the mutant phages were selected by sequencing the orf34 gene. The homogenous preparation of mutant phages was achieved by three rounds of re-plating and orf34 gene sequencing.

\section{Phage absorption assay}

The K. pneumoniae strain NTUH-K2044 was grown in $\mathrm{LB}$ broth until $\mathrm{OD}_{600}$ reaching 1.0. The bacterial culture was incubated with an equal volume of phage $\left(10^{5} \mathrm{pfu} /\right.$ $\mathrm{ml}$ ) at $37^{\circ} \mathrm{C}$ for $5 \mathrm{~min}$. Subsequently, the culture was filtered $(0.22 \mu \mathrm{m})$ and the free phages in the filtrate were counted by using the agar overlay method. The reduction in titer of free phages reflects the number of phages adsorbed on the surface of bacterial host.

\section{Animal study}

The protocol of animal study was referring to a previous report with some modification [15]. Three groups of mice, each containing five 5-week-old female BALB/ cByl mice, were inoculated intraperitoneally with $8.0 \times$ $10^{7}$ colony-forming units (CFUs) of $K$. pneumoniae strain NTUH-K2044. After $30 \mathrm{~min}$ of $K$. pneumoniae infection, the mice were administrated intraperitoneally with $25 \mu \mathrm{g}$ of the wild-type or mutant K1 lyase. The other two groups of mice were inoculated with NTHU-K2044 alone or phosphate-buffered saline as the negative and positive control, respectively. The mortality of mice was recorded for 8 days. Survival rate was analyzed by Kaplan-Meier method with a log-rank test; the difference was considered statistically significant at $P<0.05$.

To evaluate the toxicity of K1 lyase itself in mice, 4 mice were administrated intraperitoneally with $\mathrm{K} 1$ lyase at the dose of $100 \mu \mathrm{g} /$ per mouse. The change in behavior and body weight of the mice was monitored daily for 8 days. A mouse received phosphate-buffered saline alone served as the control.

\section{Results}

$\mathrm{K} 1$ lyase functions as a trimer and turns out repeating units of trisaccharide

Recombinant K1 CPS depolymerase with a His-tag was overexpressed in E. coli and purified as a homotrimeric protein (Additional file 1: Fig. S1a). The purified enzyme generated a translucent halo when spotted on agar inoculated with K1 K. pneumoniae NTUH-K2044 (Additional file 1: Fig. S1b), manifesting its CPS depolymerization activity. The products showed a UV absorption at $232 \mathrm{~nm}$ (Additional file 1: Fig. S1c), a double bond signal at $6.1 \mathrm{ppm}$ in the $1 \mathrm{D}-{ }^{1} \mathrm{H}$ NMR spectrum, and the disappearance of the signal for the $\mathrm{C}-5$ proton of the GlcA residue in the $2 \mathrm{D}-{ }^{1} \mathrm{H},{ }^{1} \mathrm{H}$ DQF-COSY spectrum (Additional file 1: Fig. S1d), indicating that the enzyme is a polysaccharide lyase [34]. Antiserum generated from the K1 CPS recognized the digested products (Fig. 1a) showing they retained the antigenicity of the intact CPS. LC-ESI-MS analyses of the degraded products revealed a major oligosaccharide $(\mathrm{m} / \mathrm{z}=1215.31)$ consisting of two trisaccharide repeating units, accompanied by two minor products $(\mathrm{m} / \mathrm{z}=1811.46$ and 619.15$)$ corresponding to oligosaccharides of one and three repeating units (Fig. 1b). Notably, all of these products retained the pyruvylation and $O$-acetylation (Fig. 1c, Additional file 1: S1e). Further characterization of the enzyme revealed a relatively high thermal stability $\left(T_{\mathrm{m}} \sim 82{ }^{\circ} \mathrm{C}\right)$ and a maximal catalytic activity at $55^{\circ} \mathrm{C}$ (Additional file 1: Fig. S1f, g). Treating the enzyme with $1 \%$ SDS led to nearly complete dissociation of the trimer into monomers, but $\sim 20 \%$ enzymatic 

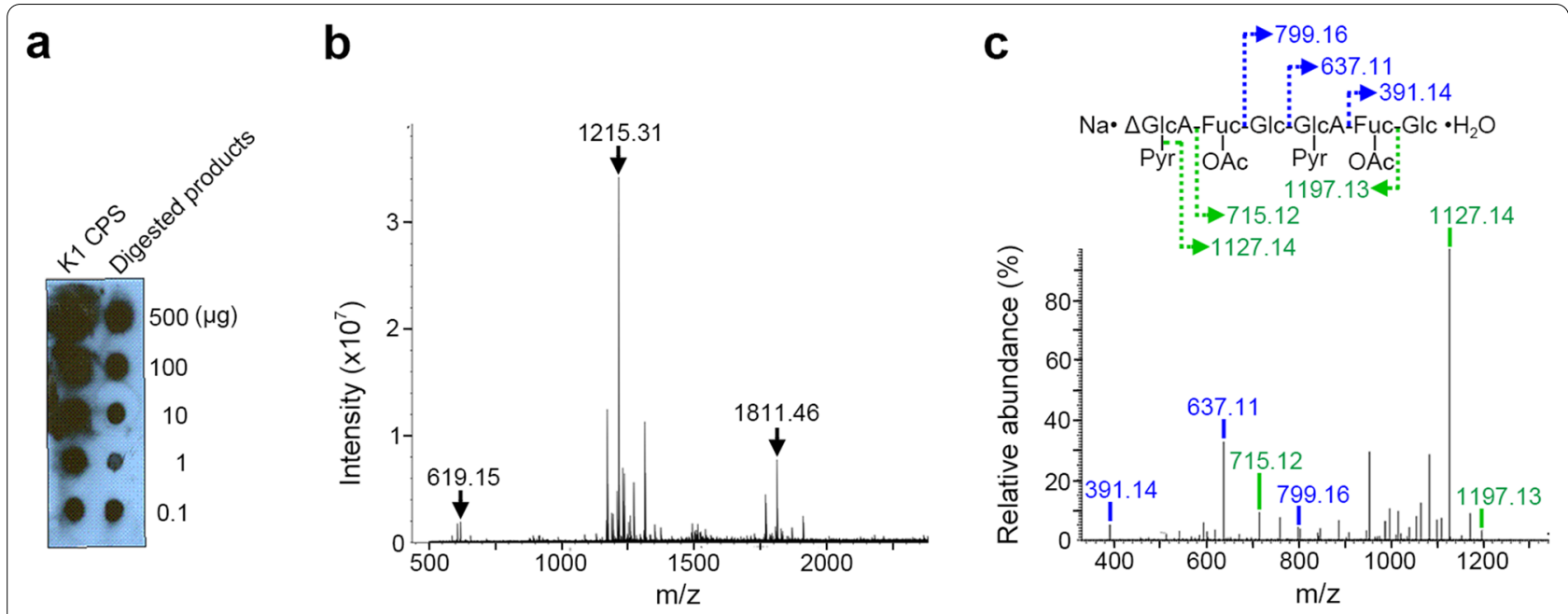

Fig. 1 Analysis of the K1 lyase-degraded products of K1 CPS. a Dot blot analysis of the K1 CPS with or without K1 lyase treatment using anti-serum generated from the K1 CPS. $\mathbf{b}$ LC-ESI-MS analysis of the K1 lyase degraded products of the K1 CPS. c LC-ESI-MS-MS analysis of the main digested product ( $\mathrm{m} / \mathrm{z}=1215.31$ ) of K1 CPS. Pyr pyruvate; OAcacetyl group the C-2 or C-3 hydroxyl groups

activity was retained (Additional file 1: Fig. S1h, i), suggesting that the trimeric structure is crucial for full CPS depolymerase activity, but that the monomer sufficiently catalyzes the lyase reaction.

\section{The overall structure of $\mathrm{K} 1$ lyase features a central $\beta$-helix for receptor binding}

The purified $\mathrm{K} 1$ lyase crystallized in the $P 1$ and $C 2$ space groups. The structure was solved by the Pt-MAD phasing method (Table 1 ). The $P 1$ crystal contains two trimers of the enzyme in an asymmetric unit, and the $C 2$ crystal has four (Additional file 1: Fig. S2a, b). Detailed structural analyses are mainly based on the $P 1$ form because of its much higher resolution. The structures revealed a compact, rod-like, trimeric molecule with an overall length of $\sim 128 \AA$ and a diameter of $\sim 86 \AA$ at its widest part (Fig. 2a-d). Only limited structural differences between the two crystal forms were observed, with an average root-mean-square (rms) deviation of $\sim 0.25 \AA$ between all $\mathrm{C} \alpha$ atoms, indicating a rigid architecture of the enzyme. The three subunits are packed side-by-side to form a parallel, left-handed superhelix. As analyzed by PDBePISA (http://www.ebi.ac.uk/pdbe/pisa), 30\% (7565 out of $24,958 \AA^{2}$ ) of the solvent-accessible surface in each subunit is buried, excluding a total surface area of 22,693 $\AA^{2}$ upon trimer formation. The shape of the monomer is reminiscent of a rider on a running horse (Fig. 2e). The body of the horse corresponds to the right-handed $\beta$-helix, from which two protruding structures constitute its "front feet" and the "rider". The putative N-terminal particle-binding domain makes up the "head", the C-terminal $\beta$-sandwich contains the "tail" and the "back feet" of the horse.

The N-terminal domain $\left(\mathrm{Glu}^{10}-\mathrm{Pro}^{70}\right)$ of each monomer folds into a barrel-like structure with a fivestranded $\beta$-sheet and a six-residue $\alpha$-helix (Fig. 3a), stabilized by three buried hydrogen bonds (H-bonds) in addition to hydrophobic interactions. A search with the DALI server (http://ekhidna.biocenter.helsinki.fi/dali_ server) revealed structural similarity to human collagen XVIII trimerization domain (by a rms deviation of $1.34 \AA$ between the C $\alpha$ atoms) (Fig. 3a, b) [35]. This fold is unusual among bacteriophage TSPs (Additional file 1: Fig. S3). In a trimer, three equivalent $\beta$-strands are laterally associated into a triangular prism but the $\alpha$-helices are solvent exposed (Fig. 2b, left panel of 3b).

\footnotetext{
(See figure on next page.)

Fig. 2 Overall structure of the K1 lyase. a The gene encoding a polysaccharide depolymerase (PDP) in the genome of bacteriophage NTUH-K2044-K1-1. The arrows represent the open reading frames 20-35 of the genome [15]. The polysaccharide depolymerase contains distinct domains, as described below, with the amino acid residues in the domains being further indicated. $\mathbf{b}, \mathbf{c}$ and $\mathbf{d}$ The trimeric structure of the enzyme drawn as three-colored ribbons in top, bottom and side view, respectively. The bound trisaccharides at the solvent-accessible groove of individual subunits and the inter-subunit pockets are shown as yellow and cyan sphere models, respectively. The view in $\mathbf{d}$ is perpendicular to the trimer axis onto a solvent-accessible groove with the $\mathrm{N}$-terminal end on top. A transparent surface is also shown. e Structure of individual subunit of K1 lyase. The domains are further indicated with colors as in a
} 


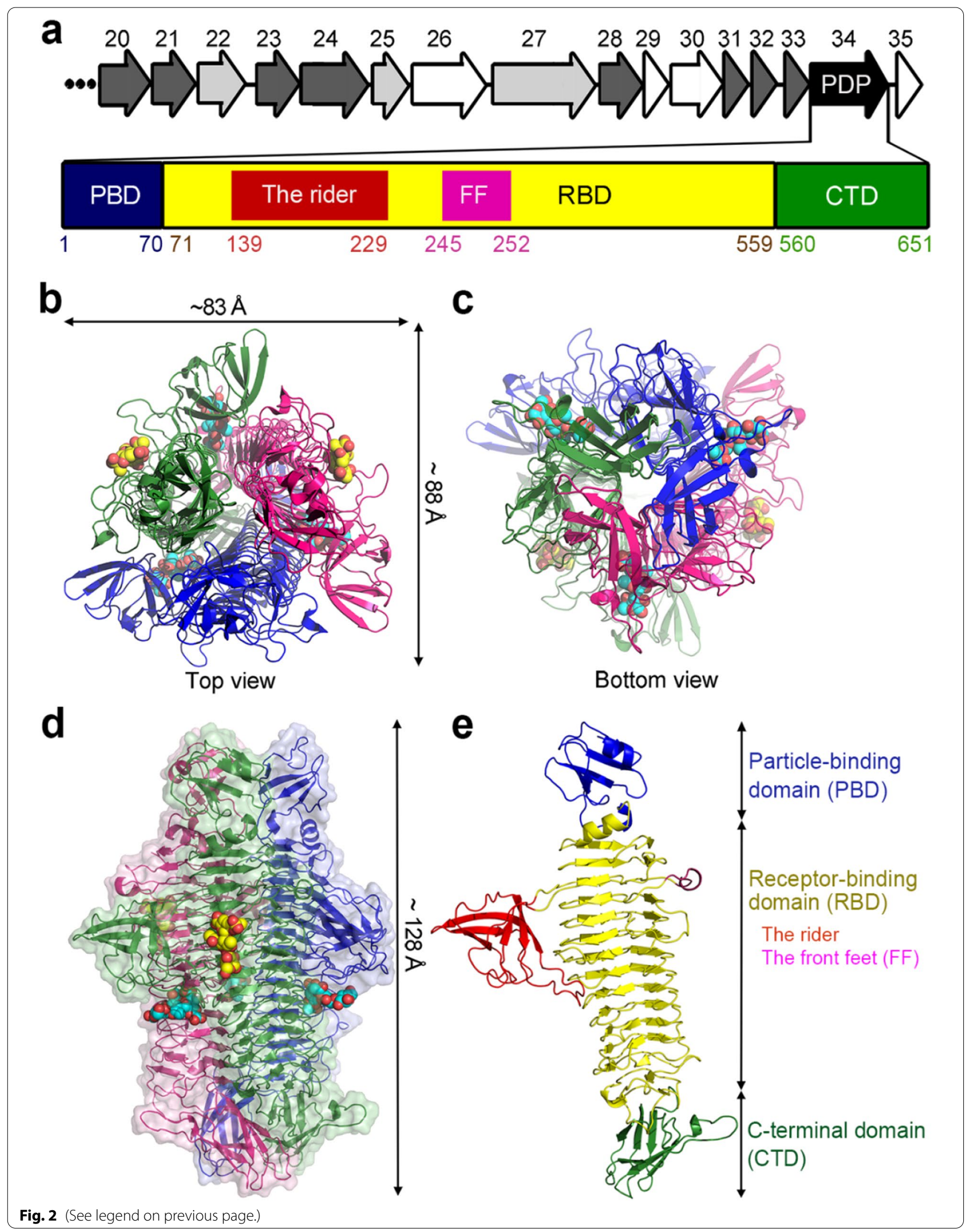




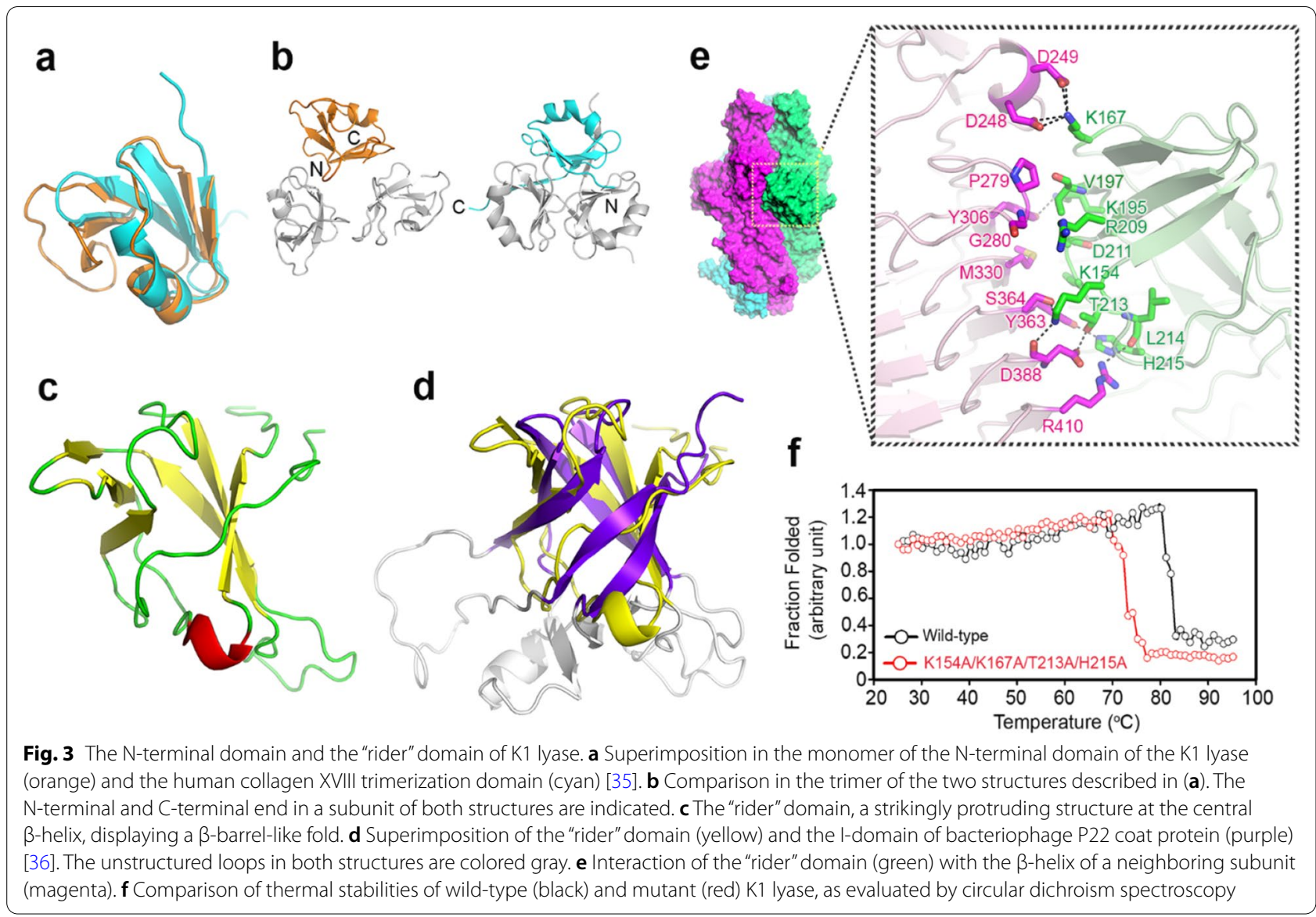

Although the trimeric association is similar to that of human collagen XVIII, the N-terminal domain of the K1 lyase has fewer stabilizing interactions. Compared to the $P 1$ structure, a slight rearrangement occurred in the $C 2$ crystal (Additional file 1: Fig. S2c), indicating the flexible nature of the $\mathrm{N}$-terminal domain.

The central receptor-binding domain $\left(\mathrm{Ala}^{71}-\mathrm{Asp}^{559}\right)$ of each monomer folds into a right-handed parallel $\beta$-helix consisting of 14 complete rungs, plus an extended $\alpha, \beta$-mixed turn on the top, where an eightresidue $\alpha$-helix covers the lumen of the $\beta$-helix, resulting in a well-formed hydrophobic core (Fig. 2e). The interior features the inward-facing stacks of $\beta$-branched or aromatic side chains (Additional file 1: Fig. S4a). The main body of the $\beta$-helix displays a kidney-shaped cross section with every rung being organized into three strands, B1, B2 and B3, separated by turns T1, T2 and T3 (Fig. 2e, Additional file 1: Fig. S4b), as seen in other TSPs (Additional file 1: Fig. S3). The parallel strands of B1, B2 and B3, respectively, merge into $\beta$-sheet b1, b2 and $b 3$ and form the three faces of the $\beta$-helix. Notably, the $\beta$-sheet b1 and turns T1 and T3 define an elongated solvent-accessible groove (Fig. 4, Additional file 1: Fig. $\mathrm{S} 4 \mathrm{~b})$, where the CPS depolymerization takes place, as described below.

Succeeding the $\beta$-helix, the polypeptide chain $\left(\mathrm{Asp}^{560}-\mathrm{Leu}^{651}\right.$ ) loops out with respect to the subunit longitudinal axis and is organized into a $\beta$-sandwich consisting of a four-stranded and a three-stranded antiparallel $\beta$-sheets plus a four-residue $3_{10}$-helix (Fig. 2e). The $\beta$-sandwich is stabilized by hydrophobic interactions in the interior and $\mathrm{H}$-bonds between loops connecting the $\beta$-strands. Furthermore, a protruding loop forms three $\mathrm{H}$-bonds to the last $\mathrm{T} 1$ turn of the $\beta$-helix. In a trimer, three $\beta$-sandwiches are associated into a dome-like structure at the trimer interface (Fig. 2c). In addition, three pairs of $\mathrm{Arg}^{555}$ and Glu ${ }^{596}$, each from a different subunit, form three inter-chain salt bridges and three intra-chain $\mathrm{H}$-bonds, constituting a triangular network that fastens the $\beta$-helix and $\beta$-sandwich domains together and firmly locks the three subunits (Additional file 1: Fig. S4c). This structure also seals off the central channel of the $\beta$-helix at the bottom. 


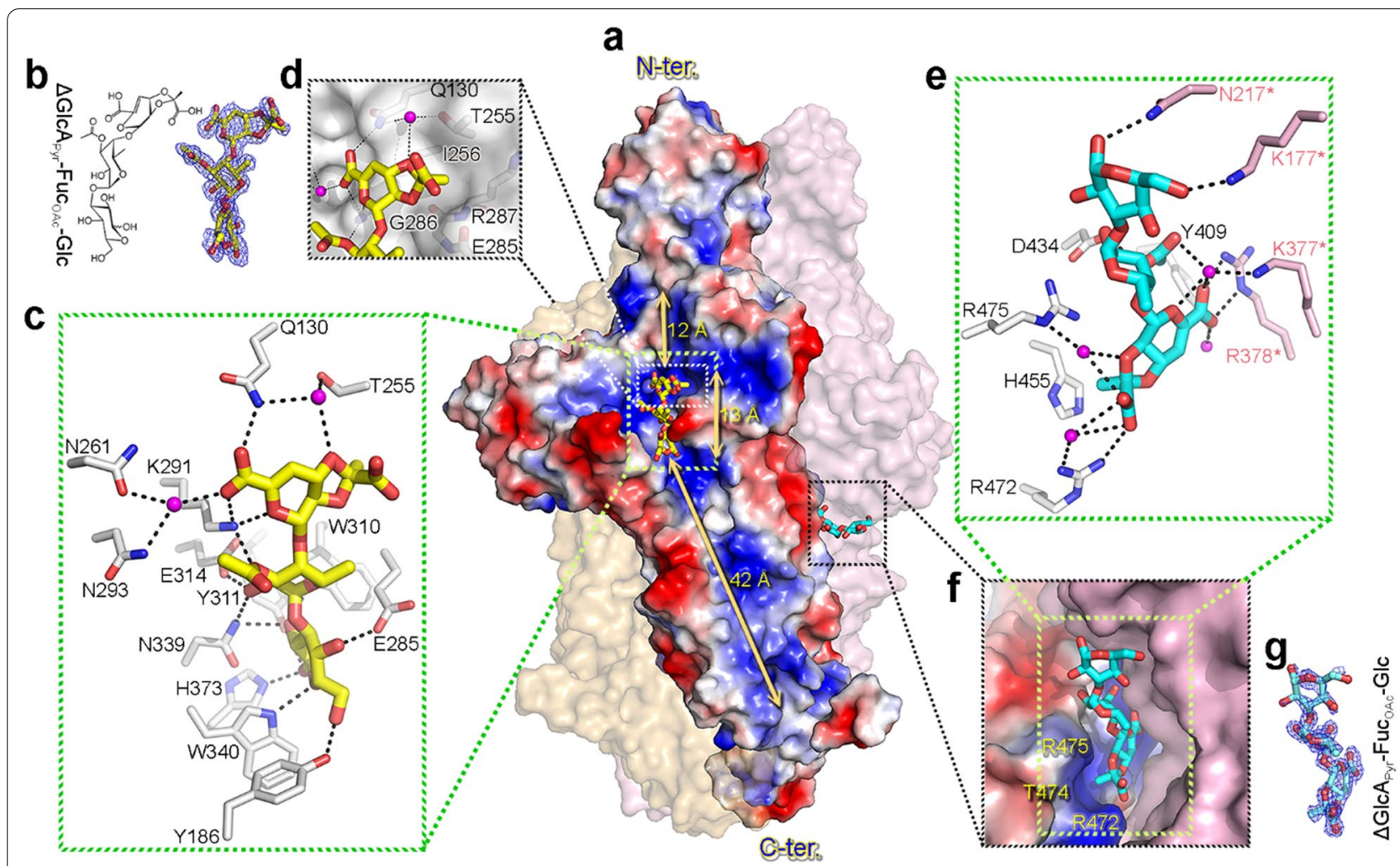

Fig. 4 Two distinct carbohydrate-binding sites with bound trisaccharides. a Surface representation of the structure of trisaccharide-bound K1 lyase, with a view the same as in Fig. $2 \mathrm{~d}$. The surface charge potentials of the subunit are shown, with blue and red color representing the positive and negative charge, respectively. The lengths for different regions of the solvent-accessible groove are indicated. $\mathbf{b}$ The chemical structure and final refined model of the bound trisaccharide at the solvent-accessible groove of a subunit. The $1 \sigma 2 F_{0}-F_{c}$ omit map around the refined model

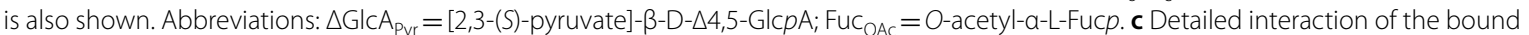
trisaccharide with the enzyme at the solvent-accessible groove. $\mathbf{d}$ The pyruvyl group of the bound trisaccharide is docked to a small pocket in the solvent-accessible groove. e Detailed interaction of the bound trisaccharide with the enzyme at the inter-subunit pocket. $\mathbf{f}$ The pyruvyl group is docked to a deep pocket created by residues $\mathrm{Arg}^{472}, \mathrm{Thr}^{474}$ and $\mathrm{Arg}^{475}$. $\mathbf{g}$ The $1 \sigma 2 F_{0}-F_{c}$ omit map around the refined model of a bound trisaccharide at the inter-subunit pocket

\section{An unusual protruding structure stabilizes the central receptor-binding domain}

While most T2 turns in the $\beta$-helix are restricted to two residues, the $\mathrm{T} 1$ and $\mathrm{T} 3$ turns vary significantly in length. In particular, $\mathrm{T} 1$ and $\mathrm{T} 3$ of rung 2 are the longest and are depicted above as the "rider" and "front feet" of a horse, respectively (Fig. 2e). The "rider" protrudes prominently from the border of the $\beta$-helix and exhibits a $\beta$-barrellike fold composed of two three-stranded antiparallel $\beta$-sheets plus a short $\alpha$-helix (Fig. 3c). The "rider" is mainly stabilized by hydrophobic interactions in the interior and four backbone $\mathrm{H}$-bonds via its extended contacts with the T1 turns of rungs $6-8$. As revealed by the DALI server, the "rider" is structurally homologous to the I-domain of bacteriophage P22 coat protein (a rms deviation of 3.20 Å between the C $\alpha$ atoms) (Fig. $3 \mathrm{~d}$ ) [36]. This I-domain was reported to be crucial to the folding and assembly of the P22 capsid [37], suggesting that the "rider" in the K1 lyase has a role in stabilizing the structure of the enzyme. On the other hand, the "front feet" section is mainly made up of a six-residue $3_{10}$-helix (Fig. 2e). This motif is stabilized by interactions with adjacent $\mathrm{T} 3$ turns via a side-chain $\mathrm{H}$-bond and van der Waals contacts.

In the trimer, three $\beta$-helices are packed laterally through the $\beta$-sheets b2 and b3, forming a parallel, lefthanded superhelix with a triangular hydrophilic channel at the center. This superhelix is stabilized by 72 $\mathrm{H}$-bonds and 18 salt bridges at the buried inter-subunit interfaces. Notably, the three "rider" domains further stabilize the superhelix (Fig. 2b-d), another uncommon feature in bacteriophage TSPs (Additional file 1: Fig. S3). The "rider" protrudes into the neighboring subunit and interacts with the "front feet" and its adjacent T3 turns (Fig. 3e). As a result, the three "rider" domains contribute $27 \mathrm{H}$-bonds and nine salt bridges, despite the modest buried interface $\left(\sim 1340 \AA^{2}\right)$. A virtually identical interaction was observed in the $C 2$ crystal (Additional file 1: 
Fig. S2d). Mutations in the "rider" domain, such as the quadruple mutant K154A/K167A/T213A/H215A, significantly reduced the thermal stability of the enzyme (Fig. 3f), providing additional support for the structural importance of the part of the protein.

\section{The central receptor-binding domain contains two distinct carbohydrate-binding sites}

The product complex structure at $1.46-\AA$ resolution showed a K1 lyase trimer bound to five trisaccharides of [2,3-(S)-pyruvate]- $\beta$-D- $\Delta 4,5$-Glc $p$ A- $(1 \rightarrow 4)$-O-acetyl$\alpha$-L-Fuc $p$ - $(1 \rightarrow 3)-\beta-\mathrm{D}-\mathrm{Gl} c p$, each corresponding to one repeating unit of the K1 CPS [10]. Unexpectedly, the bound trisaccharides revealed two distinct carbohydratebinding sites in the receptor-binding domain: the first in the solvent-accessible groove of each subunit, the second in an inter-subunit pocket beneath the "rider" (Fig. 4a). The bound trisaccharides did not induce significant conformational change of the protein (a rms deviation of $\sim 0.22 \AA$ from the free form structure between all $\mathrm{C} \alpha$ atoms), reflecting a rigid nature of the $\beta$-helix.

In the first binding site, the trisaccharide spans rungs 3-7 of the $\beta$-helix with main interactions to the protruding loops at T1 and T3 (Fig. 2d). It has an orientation nearly parallel to the longitudinal axis of the $\beta$-helix with the non-reducing end pointing to the $\mathrm{N}$-terminus (Fig. 4a). Electron densities for the pyruvylation and the planar C-4-C-5 double bond of glucuronic acid as well as the acetylation at C-3 hydroxyl group of the fucose are clear (Fig. 4b, Additional file 1: Fig. S5). Altogether, the trisaccharide binding to the enzyme is mediated by 13 direct H-bonds: three between the glucuronic acid and amino acid residues $\mathrm{Gln}^{130}$ and $\mathrm{Lys}^{291}$; three between the fucose and $\mathrm{Lys}^{291}$, Glu $^{314}$ and $\mathrm{Asn}^{339}$; and seven between the glucose and $\mathrm{Tyr}^{186}, \mathrm{Glu}^{285}, \mathrm{Trp}^{310}, \mathrm{Tyr}^{311}, \mathrm{Asn}^{339}$, $\mathrm{Trp}^{340}$ and $\mathrm{His}^{373}$ (Fig. 4c). In addition, there are four water-mediated $\mathrm{H}$-bonds between the glucuronic acid and $\mathrm{Gln}^{130}, \mathrm{Thr}^{255}, \mathrm{Asn}^{261}$ and $\mathrm{Asn}^{293}$. The trisaccharide lies in a $~ 70$ - $\AA$-long positively charged groove (Fig. 4a). The pyruvyl group of glucuronic acid fits well into a pocket lined by Ile ${ }^{256}$, Gly ${ }^{286}$ and $\mathrm{Arg}^{287}$ (Fig. 4d). Notably, the pyruvyl and acetyl groups of the trisaccharide are both involved in $\mathrm{H}$-bonding to the enzyme.

In the second binding site, the unstructured loops of the "rider" domain, the adjacent T1 and B2 of rungs 7-10 and, from a neighboring $\beta$-helix, B3 and T3 of rungs $8-11$, constitute the carbohydrate-binding pocket (Figs. 2d, 4a). The bound trisaccharide spans two adjacent $\beta$-helices and adopts an orientation nearly perpendicular to the longitudinal axis of the structure. The non-reducing end points to the central channel, with the reducing end oriented outward. The trisaccharide is stabilized by seven direct $\mathrm{H}$-bonds: three between the glucuronic acid and $\mathrm{Arg}^{472} / \mathrm{Arg}^{378 *}$ (from another subunit); two between the fucose and $\mathrm{Asp}^{434}$; and two between the glucose and Lys $^{177 *} / \mathrm{Asn}^{217 *}$ (Fig. 4e). Moreover, there are five watermediated H-bonds: four between the glucuronic acid and $\mathrm{Tyr}^{409} / \mathrm{Arg}^{472} / \mathrm{Arg}^{475} / \mathrm{Lys}^{377 *}$ and one between the fucose and Lys ${ }^{377 *}$. The pyruvyl group of the glucuronic acid is docked into a positively charged pocket formed by $\mathrm{Arg}^{472} / \mathrm{Thr}^{474} / \mathrm{Arg}^{475}$ with five H-bonds, and its methyl group makes a further $\mathrm{CH} / \pi$ interaction with the imidazole ring of $\mathrm{His}^{455}$ (Fig. 4e, f). These findings suggest that the pyruvyl group serves as a determinant for recognition by the enzyme.

It is worth noting that the bound trisaccharides adopt distinct conformations between the catalytic and noncatalytic binding sites (Fig. 4b, g, Additional file 1: Fig. S5), as evident from the strikingly different dihedral angles, i.e., $\Phi$ and $\psi$ [38], in the glycosidic linkage of $\beta$-GlcpA-(1 $\rightarrow 4)$-Fucp (Additional file 1: Table S1). This may suggest that the K1 CPS is flexible. Given the rigid architecture of the enzyme, a flexible substrate would presumably facilitate binding to both binding sites as well as the exposure of its pyruvyl group for recognition by the protein.

\section{$\mathrm{Tyr}^{311}, \mathrm{His}^{373}$ and $\mathrm{Arg}^{397}$ are important in catalysis}

Polysaccharide lyases catalyze the cleavage of uronic acid-containing polysaccharide chains via a $\beta$-elimination reaction to generate unsaturated oligosaccharide products (Additional file 1: Fig. S6) [34]. Published structures of polysaccharide lyases [34], including two derived from bacteriophage tailspikes [39, 40], have suggested residues serving as a Brønsted base/acid or neutralizer of the uronic carboxyl group. In the present study, examination of residues surrounding the bound products suggests that the catalytic site is adjacent to the reducing end of the trisaccharide in the solvent-accessible groove (Fig. 5a). Indeed, this area can be overlaid well with the proposed catalytic site of KflA, a bacteriophage-derived $\mathrm{K} 5$ lyase that is also a trimeric $\beta$-helical protein (Fig. $5 \mathrm{~b}$ ) [39]. Based on this finding, several possible catalytic residues such as $\mathrm{Lys}^{291}$, Glu ${ }^{314}$, Tyr ${ }^{311}$ and $\mathrm{His}^{373}$ were individually mutated to alanine (Fig. 5a). We found that the mutation H373A completely abolished enzymatic activity, while Y311A retained only $0.4 \%$ activity (Fig. 5 c). This is consistent with the structural observation that the side chains of $\mathrm{Tyr}^{311}$ and $\mathrm{His}^{373}$ are in proximity to the anomeric oxygen of glucose (Fig. 5a), thereby adjacent to the glucuronic acid where the $\beta$-elimination reaction occurs (Additional file 1: Fig. S6).

To identify the catalytic neutralizer of the uronic acid, we modeled a pyruvylated glucuronic acid to the reducing end as the -1 site and found candidate residues such as $\mathrm{Arg}^{333}, \mathrm{His}^{334}$ and $\mathrm{Arg}^{397}$ (Fig. 5a). Indeed, in the C2 

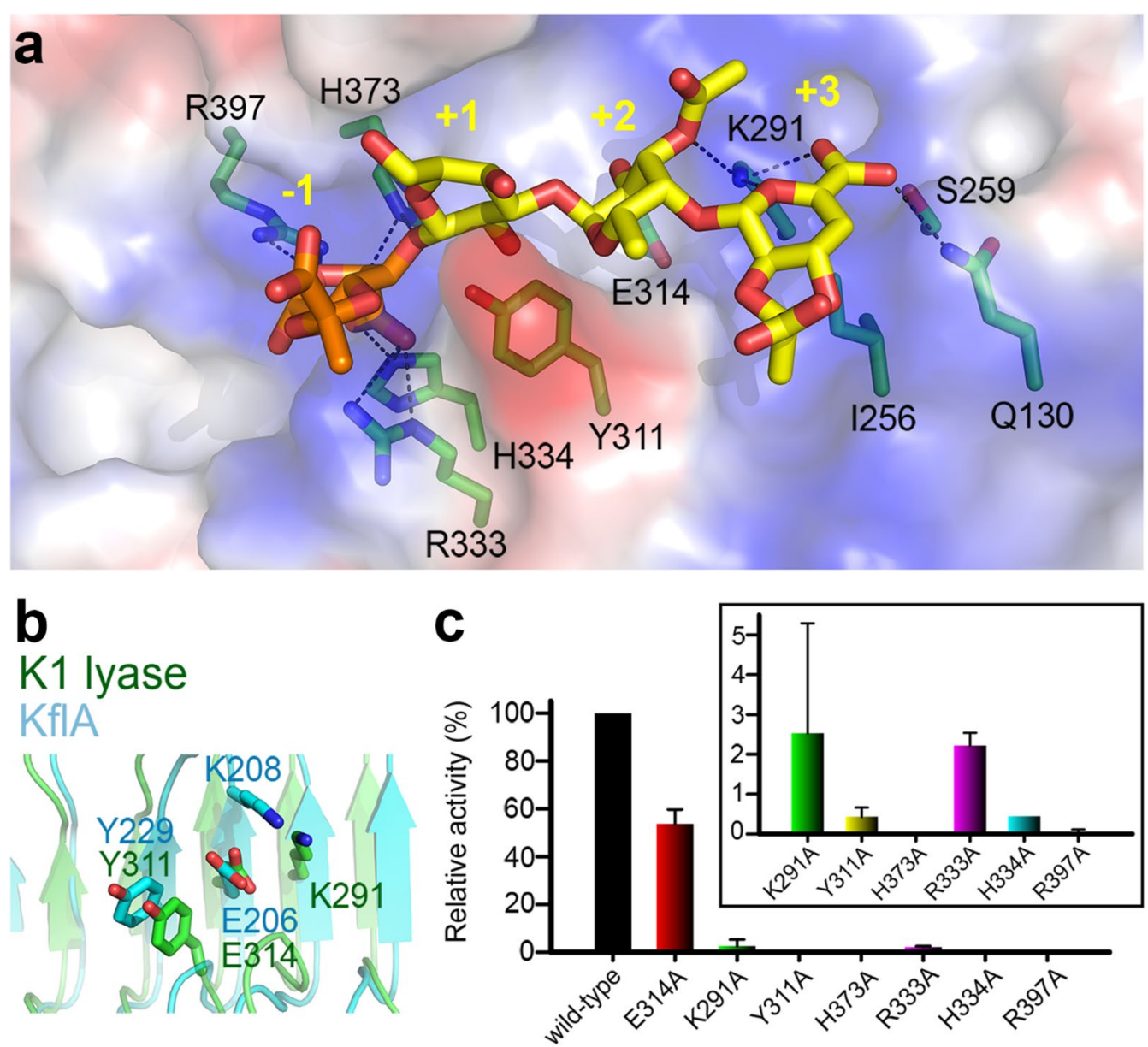

Fig. 5 The catalytic site. a The residues (green) surrounding the bound trisaccharide (yellow) at the solvent-accessible groove of an individual subunit. A pyruvylated glucuronic acid (orange) is modeled to the reducing end of the bound trisaccharide as the -1 site. b Superimposition of the catalytic center of the K1 lyase (green) with that of KflA (cyan), a bacteriophage-derived K5 lyase ${ }^{22}$. c Site-directed mutagenesis analyses of selected candidate residues that are proposed to be involved enzyme catalysis

crystal form, a citrate molecule was bound to this -1 site with its carboxyl groups forming $\mathrm{H}$-bonds to all three candidate residues (Additional file 1: Fig. S2e). Hence, these amino acids were mutated to alanine individually. We found that the mutant R397A retained only $~ 0.04 \%$ enzymatic activity (Fig. 5c). Because treatment of the enzyme with EDTA showed little effect on the enzyme activity (data not shown), and no metal ion could be identified in the present structures, we deduce that $\mathrm{Arg}^{397}$ serves as a neutralizer for the carboxyl group. Indeed, the side chains of $\mathrm{Tyr}^{311}$ and $\mathrm{His}^{373}$ are also in close proximity to the $\mathrm{C}-4$ and $\mathrm{C}-5$ atoms of the modeled glucuronic acid.
$\operatorname{Arg}^{472}$ in the second binding site, but not $\operatorname{Arg}^{378}$, is crucial to the function of $\mathrm{K} 1$ lyase and the absorption and infectivity of phage

To probe the role of the second inter-subunit pocket for polysaccharide binding $\mathrm{Arg}^{472}$ and $\mathrm{Arg}^{378}$ were mutated to alanine. These residues are involved in interactions with the pyruvyl moiety $\left(\mathrm{Arg}^{472}\right)$ and the carboxyl group $\left(\mathrm{Arg}^{378}\right)$ of the glucuronic acid of the bound trisaccharide. Mutations R472A and R472A/R378A reduced the enzyme activity to $30 \%$ and $\sim 34 \%$, respectively, but R378A had nearly no effect (Fig. 6a), suggesting that the pyruvyl group of glucuronic acid, rather than the carboxyl group, might serve as a recognition determinant for the enzyme, in agreement with the structural observations described above.

An enzyme kinetics study revealed possible product inhibition during catalysis, with a $K_{\mathrm{i}}$ value of

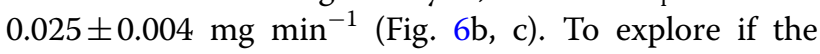



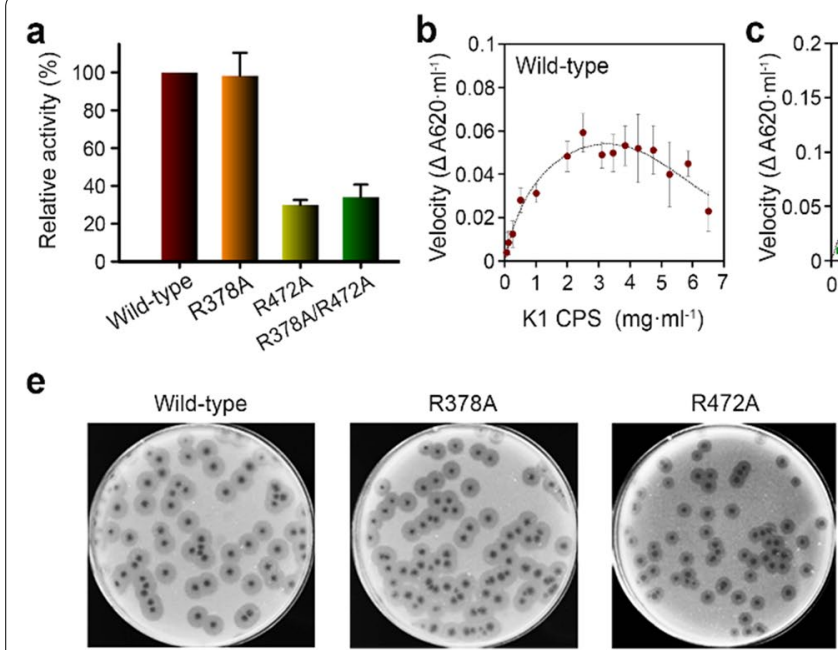

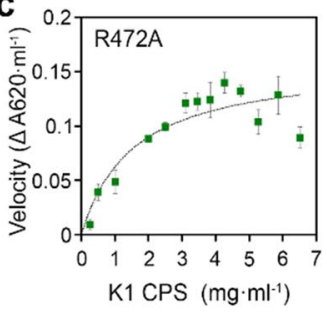

d

\begin{tabular}{lcrc} 
& $K_{\mathrm{m}}\left(\mathrm{mg} \cdot \mathrm{ml}^{-1}\right)$ & $K_{\text {cat }}\left(\mathrm{min}^{-1}\right)$ & $K_{\mathrm{i}}\left(\mathrm{mg} \cdot \mathrm{min}^{-1}\right)$ \\
\hline Wild-type & $0.81 \pm 0.13$ & $7.6 \pm 0.17$ & $0.025 \pm 0.004$ \\
\hline R472A & $2.05 \pm 0.79$ & $15.25 \pm 4.78$ & - \\
\hline
\end{tabular}

Fig. 6 Inter-subunit carbohydrate-binding site is crucial to CPS depolymerization, phage absorption and infectivity. a Comparison of CPS depolymerization activities of wild-type and mutant K1 lyases evaluated by monitoring the increase of absorbance at $232 \mathrm{~nm}$. b and $\mathbf{c}$ Enzyme kinetics study of wild-type K1 lyase and its R472A mutant, respectively. The results of initial velocity are shown as mean \pm SD from triplicate experiments. d Kinetic parameters calculated from (b) and (c). e Plaque morphology of wild-type and mutant phages. The NTUH-K2044-K1-1 phage, with or without the mutations at the coding region of the K1 lyase, were spotted on plates pre-inoculated with K1 K. pneumonia NTUH-K2044. $\mathbf{f}$ Comparison of plaque sizes of wild-type and mutant phages as evaluated by measuring the diameters of 20 randomly selected plaques. Plaques from the phage with the R472A mutation in the K1 lyase were significantly reduced in size compared to wild type $(P<0.0001$, Student's t-test), whereas the phage with the R378A mutation showed little difference $(P=0.8703)$. $\mathbf{g}$ Comparison of absorption efficiencies of wild-type and mutant phages. The phage with the R472A mutation showed decreased absorption on NTUH-K2044 compared to wild type $(P=0.0013)$, but the phage with the R378A mutation had nearly no difference $(P=0.1012)$

bound trisaccharide at the second binding site interferes with substrate binding, we analyzed the kinetics of the R472A mutant and found that product inhibition became negligible in spite of a weaker binding affinity $(\sim 2.5$-fold higher $K_{\mathrm{m}}$ value) of the mutant to the substrate (Fig. 6c, d). However, the mutant exhibited a two-fold higher turnover rate compared to that of the wild-type enzyme.

To evaluate the role of the second carbohydrate-binding site in phage infectivity, we generated two mutant phages that separately bear R378A and R472A mutations in the lyase. Remarkably, the R472A mutation reduced the plaque size of phage. On the other hand, the R378A mutation had nearly no effect (Fig. 6e, f). We also employed these mutant phages to evaluate the role of this site on phage attachment to K. pneumoniae. Absorption efficiency was attenuated by $20 \%$ in the R472A mutant whereas the R378A mutant had nearly no effect (Fig. 6g).

\section{Administration of the K1 lyase, but not an inactive mutant, significantly increases survival rate in mice pre-infected with high-doses of K. pneumonia}

A previous study showed that treatment with recombinant $\mathrm{K} 1$ lyase promoted survival in mice pre-infected with NTHU-K2044 at a dose $\left(3.3 \times 10^{3}\right.$ CFUs $)$ close to the $\mathrm{LD}_{50}$ [15]. In the present study, mice were infected

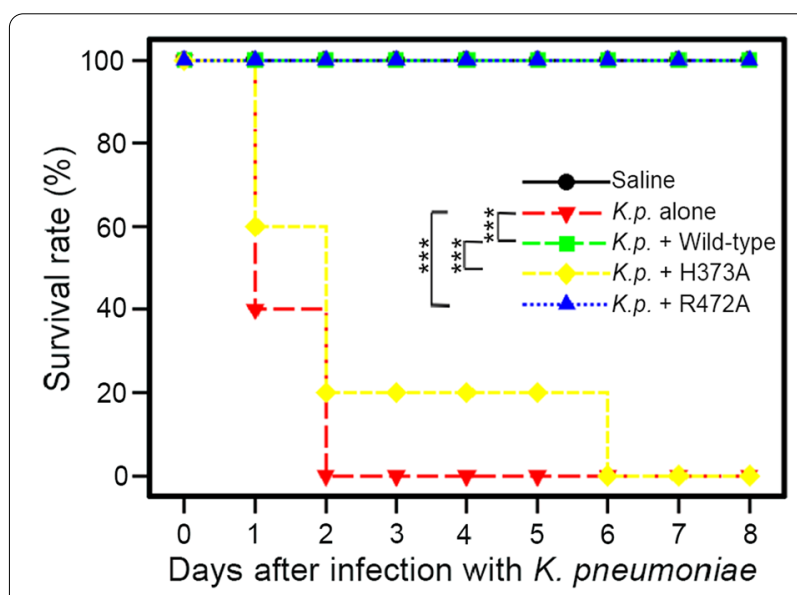

Fig. 7 Efficacies of the K1 lyase and its mutants in protecting mice from high-dose K. pneumoniae infection. Three groups of mice, each containing five 5-week-old female BALB/CByl mice, were inoculated intraperitoneally with $8.0 \times 10^{7}$ CFUs of NTHU-K2044. After $30 \mathrm{~min}$, the mice were administrated intraperitoneally with $25 \mu \mathrm{g}$ of the wild-type or mutant $\mathrm{K} 1$ lyase, as indicated. The other two groups of mice were inoculated with NTHU-K2044 alone or phosphate-buffered saline as the negative and positive control, respectively. ${ }^{* *} P<0.005$, due to log-rank test 
with a higher dose $\left(8.0 \times 10^{7} \mathrm{CFUs}\right)$ of NTHU-K2044 to further evaluate the protection efficacy of the enzyme. Intraperitoneal infection with NTHU-K2044 resulted in $100 \%$ death $(5 / 5)$ of the mice at day two, whereas all of the mice treated intraperitoneally with the $\mathrm{K} 1$ lyase (30 min after infection) survived through day eight ( $P=0.0027$, log-rank test, Fig. 7). Similarly, mice treated with the R472A mutant phage also completely survived at day eight $(P=0.0027)$, although the lyase has only $~ 30 \%$ activity compared to wild-type. In contrast, treatment with the inactive H373A mutant lyase resulted in $80 \%$ death $(4 / 5)$ at day two and $100 \%$ death at day six. There was no significant change in the behavior or body weight of the mice (Additional file 1: Fig. S7), indicating its low toxicity [41].

\section{Discussion}

Rapidly-developing molecular biology techniques and genetic tools are engendering novel and safe antimicrobial agents based on natural bacterial parasites, e.g., phages. Bacteriophage NTUH-K2044-K1-1 belongs to a new genus "Kp34likevirus" within the Podoviridae family [42]. Phages in this family share similar genome organization and conserved amino acid sequences of encoded proteins but display distinct host specificities, mainly attributed to different polysaccharide depolymerases in their tail [42]. However, the binding sites and the catalytic machineries of phage-derived polysaccharide depolymerases remain difficult to predict from sequences without $3 \mathrm{D}$-structural information.

We demonstrate here that the polysaccharide depolymerase from the bacteriophage NTUH-K2044-K1-1 is a lyase, that catalyzes a syn- $\beta$-elimination reaction using the CPS of NTUH-K2044 K. pneumoniae as a substrate. The crystal structure of the enzyme in complex with its product represents the first structure of a carbohydratebound bacteriophage-derived polysaccharide lyase. This work thus provides the first insights into how viral polysaccharide lyases recognize and depolymerize the CPS of their bacterial hosts. The structures not only exhibit typical features of bacteriophage TSPs, such as the central $\beta$-helix and the $C$-terminal $\beta$-sandwich domains, but also contain unusual features, such as an $\mathrm{N}$-terminal collagenlike trimerization fold and a striking protruding domain from the $\beta$-helix (Additional file 1: Fig. S3). Interestingly, a triple-helix bundle that connects the $\mathrm{N}$-terminal particle-binding domain and central receptor-binding domain is common in reported TSP structures but missing in the present structures (Additional file 1: Fig. S3) [39, 43, 44]. This counters the recently proposed role of the helix bundle in signal transmission from the distal tip of TSP to the phage head that eventually leads to DNA ejection [43].
Unlike other TSPs, such as the P22 TSP, KflA and ФAB6 TSPs, which contain a $\beta$-prism or triple-stranded $\beta$-helix following the central $\beta$-helix $[39,43,44]$, the K1 lyase lacks the interdigitated or swapped elements between subunits (Additional file 1: Fig. S3). The human collagen XVIII trimerization domain contains swapped loops between subunits, thus creating numerous interactions at the trimer interfaces [35], but no swapping was found in the N-terminal domain of the K1 lyase, despite the similar fold (Fig. 3b). In this regard, the buried interfaces in the present structures are probably more accessible to the solvent, accounting for the weaker tolerance of the enzyme to SDS denaturation. In contrast, the enzyme showed higher thermal stability compared to other TSPs, likely due to the additional stabilization contributed by the protruding "rider" domain, as supported by our mutagenesis study. It is intriguing to contemplate engineering the $\mathrm{N}$-terminal domain to be even more collagen-like to further improve thermal stability.

The striking protruding domain at the central $\beta$-helix described here is uncommon in bacteriophage TSPs (Additional file 1: Fig. S3) [39, 43-46]. The P22 TSP structure also has a protruding domain on the central $\beta$-helix, displaying a shape like the dorsal fin of a fish [43]. However, unlike the "rider" of the K1 lyase, the "dorsal fin" of P22 TSP is located in a T3 turn and makes only a slight contact with the neighboring $\beta$-helix. This "dorsal fin" does not interact with the polysaccharide substrate [47]. In contrast, the "rider" of K1 lyase participates in polysaccharide binding to both carbohydrate-binding sites and makes an important contribution to the structural stability of the trimeric enzyme.

The first carbohydrate-binding site of the $\mathrm{K} 1$ lyase is in an elongated positively-charged groove that extends longitudinally for $\sim 70 \AA$. The distance between the reducing end of the bound trisaccharide and the $\mathrm{C}$-terminal end of the enzyme is more than $40 \AA$ (Fig. 4a). Thus, this solventaccessible groove is capable of accommodating oligosaccharides up to three repeating units, likely reflecting the maximum size of K1 CPS degradation products. Thirteen direct $\mathrm{H}$-bonds stabilize the trisaccharide product at the groove with seven between the reducing-end glucose and the enzyme. Prediction of $\mathrm{p} K_{\mathrm{a}}$ values for nearby ionizable residues with the PDB2PQR server (http://nbcr-222.ucsd. edu/pdb2pqr_2.1.1) indicates that the $\mathrm{p} K_{\mathrm{a}}$ of $\mathrm{Tyr}^{311}$ shifts from 10.07 to 13.24 , and $\mathrm{His}^{373}$ from 6.10 to 3.44 , suggesting that $\mathrm{Tyr}^{311}$ and $\mathrm{His}^{373}$ serve as the Brønsted base and acid, respectively. Consequently, the above $\mathrm{H}$-bond network probably forces the anomeric oxygen of glucose in the polysaccharide to be in the proximity of $\mathrm{Tyr}^{311}$ and $\mathrm{His}^{373}$, facilitating catalysis. In addition, according to its position near the carboxyl group of the modeled glucuronic acid, and supported by mutagenesis analysis, $\mathrm{Arg}^{397}$ 
probably serves as a neutralizer to lower the $\mathrm{p} K_{\mathrm{a}}$ value of the $\mathrm{C}-5$ proton of the glucuronic acid.

This study provides the first direct evidence to identify a second, non-catalytic, carbohydrate-binding site in bacteriophage TSPs. The bound trisaccharide at the inter-subunit binding site occupies most of the pocket, and its non-reducing end nearly reaches the bottom, suggesting that the pocket can only accommodate the terminal portion of the K1 CPS. Although the depolymerization reaction takes place in each individual subunit, the results from SDS dissociation and mutagenesis analysis indicate that the inter-subunit binding site plays an important role in CPS depolymerization. Furthermore, this inter-subunit binding pocket is also important for phage attachment and infection to $K$. pneumoniae, as supported by the results from phage absorption and infectivity studies. Notably, the pyruvyl group of the bound trisaccharide at the non-catalytic site is embedded deep in a pocket, reminiscent of the pseudaminic acid in the surface polysaccharide of the bacterium Acinetobacter baumannii [48]. This pseudaminic acid serves as a recognition site for ФAB6 TSP, another bacteriophage-derived polysaccharide hydrolase [48]. In this regard, the pyruvyl group of K1 CPS might likewise serve as a recognition site for K1 lyase. Through a mutagenesis study, we demonstrated that the interaction between the pyruvyl group and the enzyme is crucial to CPS depolymerization and phage absorption and infection. Indeed, the pyruvyl group of K1 CPS has been reported to be an important recognition site for the host immune system $[10,49]$. This implies that the pyruvylation site can be a target for designing vaccines and therapeutic antibodies.

Bacteriophage polysaccharide depolymerases that recognize specific exopolysaccharides of pathogenic bacteria can be advantageous in therapeutic use, such as selective killing of a pathogen without affecting normal microflora and reducing the development of antibiotic resistance [50]. In the present study, we demonstrate that the K1 lyase protects mice from K1 K. pneumoniae infection, even with a high challenge dose. Presumably, the enzyme removes the CPS from the bacteria and the loss of capsule enables the host killing by the immune system. The lack of adverse effects in the mice suggests low toxicity of the enzyme. We also demonstrated that the K1 lyase-digested CPS products contained pyruvylation and $O$-acetylation, thus retaining the important antigens of intact K1 CPS, as evident from the observation that the antiserum against intact K1 CPS strongly recognized the digested products. The finding that a single-residue mutation at the second carbohydratebinding site of $\mathrm{K} 1$ lyase resulted in negligible product inhibition during catalysis might provide clues to protein engineering for optimizing the catalytic efficiency of the enzyme. These results imply the application of this enzyme as well as its digested products in preparation of therapeutic agents and glycoconjugate vaccines against PLA K. pneumoniae infection.

\section{Conclusions}

We demonstrate here that the K1 lyase from the NTUHK2044-K1-1 bacteriophage is a polysaccharide depolymerase that cleaves the CPS into oligosaccharides of 1-3 repeating trisaccharide units with the retention of the pyruvylation and $O$-acetylation. This enzyme has a trimeric $\beta$-helix architecture and contains two distinct carbohydrate-binding sites. One is responsible for CPS depolymerization via a syn $\beta$-elimination mechanism that involves $\mathrm{Tyr}^{311}, \mathrm{His}^{373}$ and $\mathrm{Arg}^{397}$. The other also recognizes and binds to CPS but is not catalytic, and a single-residue mutation, $\mathrm{R} 472 \mathrm{~A}$ in this site, liberated the enzyme from product inhibition during catalysis. The tight interaction between the pyruvate moiety of the CPS and the enzyme in the second binding site, mediated by $\mathrm{Arg}^{472}$, is also crucial to CPS depolymerization as well as phage absorption and infectivity. Administration of the enzyme, but not an inactive mutant, protected mice from infection by a high-dose of K1 K. pneumonia without significant adverse effects. Our results provide insights into how the enzyme recognizes and depolymerizes the CPS, and demonstrate the potential use of the protein not only as a therapeutic agent against $K$. pneumoniae, but also as a tool to prepare structurally-defined oligosaccharides for the generation of glycoconjugate vaccines against infections caused by this organism.

\section{Abbreviations \\ CPS: Capsular polysaccharide; PLA: Pyogenic liver abscess; TSP: Tailspike protein.}

\section{Supplementary Information}

The online version contains supplementary material available at https://doi. org/10.1186/s12929-022-00792-4.

Additional file 1: Figure S1. Characterization of recombinant K1 lyase. Figure S2. Crystal structure of K1 lyase in the C2 crystal form. Figure S3. Comparison of the $\mathrm{K} 1$ lyase structure described here with some reported structures of bacteriophage-derived CPS depolymerases. Figure S4. The inward and outward side-chain stacks and the triangular interaction network at the central $\beta$-helix of K1 lyase. Figure S5. The 2Fo-Fc omit maps for the bound trisaccharides [2,3-(S)-pyruvate]- $\beta$-D- $\triangle 4,5-G$ lcpA- $(1 \rightarrow 4)-0$ acetyl-a-L-Fucp- $(1 \rightarrow 3)-\beta$-D-Glcp at the first (or catalytic) and second (or non-catalytic) binding sites. Figure S6. Schematic illustration of the sym $\beta$-elimination reaction catalyzed by K1 lyase. Figure S7. Effect of highdose K1 lyase on the survival rate and body weight of mice. Table S1. The dihedral angles $(\Phi, \psi)$ of glycosidic linkages of the bound trisaccharides at the catalytic and non-catalytic binding sites of K1 lyase. 


\section{Acknowledgements}

We acknowledge the Protein X-ray Crystallography Facility of the Institute of Biological Chemistry, Biophysics Core Facility of Scientific Instrument Center, the MS Core Facility of Genomic Research Center, and the High Field Nuclear Magnetic Resonance Center (Grant No. AS-CFII-108-112), Academia Sinica for support in using the instruments. We thank the support from Taiwan Protein Project (Grant No. AS-KPQ-109-TPP2). We also thank the staffs of beamlines 15A1, 13B1, and 13C1 at the National Synchrotron Radiation Research Center (Hsinchu, Taiwan), beamlines 44XU and 12B2 at SPring-8 (Hyogo, Japan) and the Molecular Biology Consortium beamline at Advanced Light Source (Berkeley, USA) for assistances in X-ray data collection. We are also grateful to Prof. Todd L. Lowary in our Institute for careful reading and critical comments on the manuscript.

\section{Authors' contributions}

I-FT, T-LL, K-FH, and S-HW conceived and designed the experiments; I-FT, T-LL, F-LY, I-ML, W-LT, J-HL, T-PK, W-JW, M-RH and K-FH performed the experiments; I-FT, T-LL, I-ML, C-YC, T-PK, and K-FH analyzed and interpreted the data; J-TW, $\mathrm{J}-\mathrm{TJ}$ and C-YW contributed reagents/materials/analysis tools; I-FT and K-FH prepared the original draft and F-LY, T-PK and S-HW reviewed and edited the manuscript; J-TW, AH-JW, K-FH and S-HW supervised the study; all authors read and approved the final manuscript.

\section{Funding}

This work was supported by grants from Ministry of Sciences and Technology (MOST-108-2113-M-001-008 to S-HW) and from Academia Sinica (AS-KPQ110-ITAR-11 to K-FH and AH-JW).

\section{Availability of data and materials}

The atomic coordinates and structure factors of the crystal structures in this study have been deposited in the Protein Data Bank (www.wwpdb.org) under accession codes 7W1C, 7W1D and 7W1E. Other data and materials are available from the corresponding authors on reasonable request.

\section{Declarations}

\section{Ethics approval and consent to participate}

The care and use of mice protocols were approved by Biomedical Translation Research Center, Academia Sinica.

\section{Consent for publication}

Not applicable.

\section{Competing interests}

The authors declare no competing interests.

\begin{abstract}
Author details
${ }^{1}$ Institute of Biological Chemistry, Academia Sinica, No. 128 Academia Road Section 2, Nan-Kang, Taipei 115, Taiwan. ${ }^{2}$ Department of Microbiology, National Taiwan University Hospital, Taipei 100, Taiwan. ${ }^{3}$ Genomics Research Center, Academia Sinica, Taipei 115, Taiwan. ${ }^{4}$ Department of Chemistry, National Taiwan University, Taipei 106, Taiwan.
\end{abstract}

Received: 22 December 2021 Accepted: 24 January 2022

Published online: 07 February 2022

\section{References}

1. Siu LK, Yeh KM, Lin JC, Fung CP, Chang FY. Klebsiella pneumoniae liver abscess: a new invasive syndrome. Lancet Infect Dis. 2012;12(11):881-7.

2. Shon AS, Bajwa RP, Russo TA. Hypervirulent (hypermucoviscous) Klebsiella pneumoniae: a new and dangerous breed. Virulence. 2013;4(2):107-18.

3. Fung CP, Chang FY, Lee SC, Hu BS, Kuo BI, Liu CY, Ho M, Siu LK. A global emerging disease of Klebsiella pneumoniae liver abscess: is serotype K1 an important factor for complicated endophthalmitis? Gut. 2002;50(3):420-4.

4. Wu MF, Yang CY, Lin TL, Wang JT, Yang FL, Wu SH, Hu BS, Chou TY, Tsai MD, Lin CH, Hsieh SL. Humoral immunity against capsule polysaccharide protects the host from magA+ Klebsiella pneumoniae-induced lethal disease by evading Toll-like receptor 4 signaling. Infect Immun. 2009;77(2):615-21.

5. Diago-Navarro E, Calatayud-Baselga I, Sun D, Khairallah C, Mann I, UlaciaHernando A, Sheridan B, Shi M, Fries BC. Antibody-based immunotherapy to treat and prevent infection with hypervirulent Klebsiella pneumoniae. Clin Vaccine Immunol. 2017;24(1):e00456-e516.

6. Howard JG. T-cell independent responses to polysaccharides, their nature and delayed ontogeny. Science. 1987;215:221-9.

7. Vella M, Pace D. Glycoconjugate vaccines: an update. Expert Opin Biol Ther. 2015;15(4):529-46.

8. Avci FY, Kasper DL. How bacterial carbohydrates influence the adaptive immune system. Annu Rev Immunol. 2010;28:107-30.

9. Avci FY, Li X, Tsuji M, Kasper DL. A mechanism for glycoconjugate vaccine activation of the adaptive immune system and its implications for vaccine design. Nat Med. 2011;17(12):1602-9.

10. Yang FL, Yang YL, Liao PC, Chou JC, Tsai KC, Yang AS, Sheu F, Lin TL, Hsieh PF, Wang JT, Hua KF, Wu SH. Structure and immunological characterization of the capsular polysaccharide of a pyrogenic liver abscess caused by Klebsiella pneumoniae: activation of macrophages through Toll-like receptor 4. J Biol Chem. 2011;286(24):21041-51.

11. Feldman MF, Mayer Bridwell AE, Scott NE, Vinogradov E, McKee SR, Chavez SM, Twentyman J, Stallings CL, Rosen DA, Harding CM. A promising bioconjugate vaccine against hypervirulent Klebsiella pneumoniae. Proc Natl Acad Sci USA. 2019;116(37):18655-63.

12. Pires DP, Oliveira H, Melo LD, Sillankorva S, Azeredo J. Bacteriophageencoded depolymerases: their diversity and biotechnological applications. Appl Microbiol Biotechnol. 2016;100(5):2141-51.

13. Geyer H, Schlecht S, Himmelspach K. Immunochemical properties of oligosaccharide-protein conjugates with Klebsiella-K2-specificity. II. Protective capacity of the conjugates and anti-conjugate antibodies against infection with Klebsiella pneumoniae 01:K2 in mice. Med Microbiol Immunol. 1982;171(3):135-43.

14. Geyer H, Stirm S, Himmelspach K. Immunochemical properties of oligosaccharide-protein conjugates with Klebsiella-K2 specificity. I. Specificity and crossreactivity of anti-conjugate versus anti-bacterial antibodies. Med Microbiol Immunol. 1979;165(4):271-88.

15. Lin TL, Hsieh PF, Huang YT, Lee WC, Tsai YT, Su PA, Pan YJ, Hsu CR, Wu MC, Wang JT. Isolation of a bacteriophage and its depolymerase specific for $\mathrm{K} 1$ capsule of Klebsiella pneumoniae: implication in typing and treatment. J Infect Dis. 2014;210(11):1734-44.

16. Pan YJ, Lin TL, Lin YT, Su PA, Chen CT, Hsieh PF, Hsu CR, Chen CC, Hsieh YC, Wang JT. Identification of capsular types in carbapenem-resistant Klebsiella pneumoniae strains by wzc sequencing and implications for capsule depolymerase treatment. Antimicrob Agents Chemother. 2015;59(2):1038-47.

17. Wilkins MR, Gasteiger E, Bairoch A, Sanchez JC, Williams KL, Appel RD, Hochstrasser DF. Protein identification and analysis tools in the ExPASy server. Methods Mol Biol. 1999;112:531-52.

18. Verma V, Harjai K, Chhibber S. Characterization of a T7-like lytic bacteriophage of Klebsiella pneumoniae B5055: a potential therapeutic agent. Curr Microbiol. 2009;59(3):274-81.

19. Chuang YP, Fang CT, Lai SY, Chang SC, Wang JT. Genetic determinants of capsule serotype $\mathrm{K} 1$ of Klebsiella pneuminiae causing primary pyogenic liver abscess. J Infect Dis. 2006;193(5):645-54.

20. Little DJ, Pfoh R, Le Mauff F, Bamford NC, Notte C, Baker P, Guragain M, Robinson H, Pier GB, Nitz M, Deora R, Sheppard DC, Howell PL. PgaB orthologues contain a glycoside hydrolase domain that cleaves deacetylated poly- $\beta(1,6)-N$-acetylglucosamine and can disrupt bacterial biofilms. PLoS Pathog. 2018;14(4):e1006998.

21. Mendes P, Messiha H, Malys N, Hoops S. Enzyme kinetics and computational modelling for system biology. Methods Enzymol. 2009;467:583-99.

22. Otwinowski Z, Minor W. Processing of X-ray diffraction data collected in oscillation mode. Methods Enzymol. 1997;276:307-26.

23. Sheldrick GM. A short history of SHELX. Acta Crystallogr A. 2008;64(Pt 1):112-22.

24. Pannu NS, Read RJ. The application of multivariate statistical techniques improves single-wavelength anomalous diffraction phasing. Acta Crystallogr D Biol Crystallogr. 2004;60(Pt 1):22-7.

25. Abrahams JP, Leslie AG. Methods used in the structure determination of bovine mitochondrial F1 ATPase. Acta Crystallogr D Biol Crystallogr. 1996;52(Pt 1):30-42. 
26. Cowtan K. The Buccaneer software for automated model building. 1. Tracing protein chains. Acta Crystallogr D Biol Crystallogr. 2006;62(Pt 9):1002-11.

27. Emsley P, Cowtan K. Coot: model-building tools for molecular graphics. Acta Crystallogr D Biol Crystallogr. 2004;60(Pt 12):2126-32.

28. Murshudov GN, Skubák P, Lebedev AA, Pannu NS, Steiner RA, Nicholls RA, Winn MD, Long F, Vagin AA. REFMAC5 for the refinement of macromolecular crystal structures. Acta Crystallogr D Biol Crystallogr. 2011;67(Pt 4):355-67.

29. Laskowski RA, MacArthur MW, Moss DS, Thornton JM. PROCHECK: a program to check the stereochemical quality of protein structures. J Appl Cryst. 1993;26(Pt 2):283-91.

30. Vagin A, Teplyakov A. Molecular replacement with MOLREP. Acta Crystallogr D Biol Crystallogr. 2010;66(Pt 1):22-5.

31. Pan YJ, Lin TL, Chen CC, Tsai YT, Cheng YH, Chen YY, Hsieh PF, Lin YT, Wang JT. Klebsiella phage ФK64-1 encodes multiple depolymerases for multiple host capsular types. J Virol. 2017;91(6):e02457-e2516.

32. Marinelli LJ, Piuri M, Swigonová Z, Balachandran A, Oldfield LM, van Kessel JC, Hatfull GF. BRED: a simple and powerful tool for constructing mutant and recombinant bacteriophage genomes. PLOS ONE. 2008;3(12):e3957.

33. Datsenko KA, Wanner BL. One-step inactivation of chromosomal genes in Escherichia coli K-12 using PCR products. Proc Natl Acad Sci USA. 2000;97(12):6640-5

34. Garron ML, Cygler M. Structural and mechanistic classification of uronic acid-containing polysaccharide lyases. Glycobiology. 2010;20(12):1547-73.

35. Boudko SP, Sasaki T, Engel J, Lerch TF, Nix J, Chapman MS, Bächinger HP. Crystal structure of human collagen XVIII trimerization domain: A novel collagen trimerization fold. J Mol Biol. 2009;392(3):787-802.

36. Rizzo AA, Suhanovsky MM, Baker ML, Fraser LC, Jones LM, Rempel DL, Gross ML, Chiu W, Alexandrescu AT, Teschke CM. Multiple functional roles of the accessory l-domain of bacteriophage P22 coat protein revealed by NMR structure and CryoEM modeling. Structure. 2014;22(6):830-41.

37. D'Lima NG, Teschke CM. A molecular staple: D-Loops in the I domain of bacteriophage P22 coat protein make important intercapsomer contacts required for procapsid assembly. J Virol. 2015;89(20):10569-79.

38. Broeker NK, Andres D, Kang Y, Gohlke U, Schmidt A, Kunstmann S, Santer M, Barbirz S. Complex carbohydrate recognition by proteins: Fundamental insights from bacteriophage cell adhesion systems. Perspect Sci. 2017:11:45-52.

39. Thompson JE, Pourhossein M, Waterhouse A, Hudson T, Goldrick M, Derrick JP, Roberts IS. The K5 lyase KflA combines a viral tail spike structure with a bacterial polysaccharide lyase mechanism. J Biol Chem. 2010;285(31):23963-9.

40. Mishra P, Prem Kumar R, Ethayathulla AS, Singh N, Sharma S, Perbandt M, Betzel C, Kaur P, Srinivasan A, Bhakuni V, Singh TP. Polysaccharide binding sites in hyaluronate lyase-crystal structures of native phage-encoded hyaluronate lyase and its complexes with ascorbic acid and lactose. FEBS J. 2009;276(12):3392-402

41. Lin H, Paff ML, Molineux IJ, Bull JJ. Therapeutic application of phage capsule depolymerases against K1, K5, and K30 capsulated E. coli in mice. Front Microbiol. 2017;8:2257.

42. Eriksson $\mathrm{H}$, Maciejewska B, Latka A, Majkowska-Skrobek G, Hellstrand M, Melefors Ö, Wang JT, Kropinski AM, Drulis-Kawa Z, Nilsson AS. A suggested new bacteriophage genus, "Kp34likevirus", within the Autographivirinae subfamily of Podoviridae. Viruses. 2015;7(4):1804-22.

43. Seul A, Müller JJ, Andres D, Stettner E, Heinemann U, Seckler R. Bacteriophage P22 tailspike: structure of the complete protein and function of the interdomain linker. Acta Crystallogr D Biol Crystallogr. 2014;70(Pt 5):1336-45

44. Lee IM, Tu IF, Yang FL, Ko TP, Liao JH, Lin NT, Wu CY, Ren CT, Wang AH, Chang CM, Huang KF, Wu SH. Structural basis for fragmenting the exopolysaccharide of Acinetobacter baumannii by bacteriophage PhiAB6 tailspike protein. Sci Rep. 2017;7:42711.

45. Squeglia F, Maciejewska B, Łątka A, Ruggiero A, Briers Y, Drulis-Kawa Z, Berisio R. Structural and functional studies of a Klebsiella phage capsule depolymerase tailspike: mechanistic insights into capsular degradation. Structure. 2020;28(6):613-24.

46. Olszak T, Shneider MM, Latka A, Maciejewska B, Browning C, Sycheva LV, Cornelissen A, Danis-Wlodarczyk K, Senchenkova SN, Shashkov AS, Gula G, Arabski M, Wasik S, Miroshnikov KA, Lavigne R, Leiman PG, Knirel YA,
Drulis-Kawa Z. The O-specific polysaccharide lyase from the phage LKA1 tailspike reduces Pseudomonas virulence. Sci Rep. 2017;7(1):16302.

47. Steinbacher S, Baxa U, Miller S, Weintraub A, Seckler R, Huber R. Crystal structure of phage P22 tailspike protein complexed with Salmonella sp. O-antigen receptors. Proc Natl Acad Sci U S A. 1996;93(20):10584-8.

48. Lee IM, Yang FL, Chen TL, Liao KS, Ren CT, Lin NT, Chang YP, Wu CY, Wu SH. Pseudaminic acid on exopolysaccharide of Acinetobacter baumannii plays a critical role in phage-assisted preparation of glycoconjugate vaccine with high antigenicity. J Am Chem Soc. 2018;140(28):8639-43.

49. Hua KF, Yang FL, Chiu HW, Chou JC, Dong WC, Lin CN, Lin CY, Wang JT, Li LH, Chiu HW, Chiu YC, Wu SH. Capsular polysaccharide is involved in NLRP3 inflammasome activation by Klebsiella pneumoniae serotype K1. Infect Immun. 2015;83(9):3396-409.

50. Maciejewska B, Olszak T, Drulis-Kawa Z. Applications of bacteriophages versus phage enzymes to combat and cure bacterial infections: an ambitious and also a realistic application? Appl Microbiol Biotechnol. 2018;102(6):2563-81.

\section{Publisher's Note}

Springer Nature remains neutral with regard to jurisdictional claims in published maps and institutional affiliations.
Ready to submit your research? Choose BMC and benefit from:

- fast, convenient online submission

- thorough peer review by experienced researchers in your field

- rapid publication on acceptance

- support for research data, including large and complex data types

- gold Open Access which fosters wider collaboration and increased citations

- maximum visibility for your research: over $100 \mathrm{M}$ website views per year

At BMC, research is always in progress.

Learn more biomedcentral.com/submissions 